Published in "Transport in Porous Media 129(1): 343-383, 2019"

which should be cited to refer to this work.

\title{
An Analytical Algorithm of Porosity-Permeability for Porous and Fractured Media: Extension to Reactive Transport Conditions and Fitting via Flow-Through Experiments Within Limestone and Dolomite
}

\author{
Selçuk Erol ${ }^{1,2} \cdot$ Sarah Jane Fowler ${ }^{3} \cdot$ Mathias Nehler $^{4} \cdot$ Eva De Boever ${ }^{5}$. \\ Virginie Harcouët-Menou ${ }^{1} \cdot$ Ben Laenen ${ }^{1}$
}

\begin{abstract}
Accurate prediction of permeability evolution is essential for forecasting the long-term performance and lifetime of hydrothermal reservoirs, an important goal in the geothermal, ore, and petroleum industries. Erol et al. (Transp Porous Media 120(2):327-358, 2017. https://doi.org/10.1007/s11242-017-0923-z) introduced a general (non-empirical) analytical Kozeny-Carman type equation for predicting matrix and fracture permeability during single-phase, non-reactive flow. Here we incorporate the equation into an algorithm for addressing the influence on porous and fractured media permeability of the transient reactive processes of mineral dissolution and precipitation. Analytical algorithm predictions are identical to permeability values measured during fluid circulation through limestone and dolomite core samples from the Campine Basin deep geothermal system in Belgium. Benchmarking used identical values for initial hydraulic aperture dimension and porosity, measured during fluid circulation based on nondestructive micro-CT imaging. Analytical algorithm predictions of reactive surface area and fracture porosity are similar to results based on the TOUGHREACT reactive transport code. TOUGHREACT implements several well-established power-law models for predicting permeability, notably Civan (AIChE J 47(2):1167-1197, 2001. https://doi.org/10.1002/aic.690470206) and Verma and Pruess (J Geophys Res Solid Earth 93:1159-1173, 1988. https://doi.org/10.1029/jb093ib02p01159). However, these models rely on specification of empirical exponents, which are not straightforward to measure. Our results suggest that a more general, computationally inexpensive analytical method can lead to accurate permeability calculation.
\end{abstract}

Keywords Reactive transport $\cdot$ Dual porosity $\cdot$ Permeability $\cdot$ Carbonate $\cdot$ Geothermal

List of Symbols

a Pore radius (m)

A Cross-sectional area $\left(\mathrm{m}^{2}\right)$

$D_{\mathrm{fm}} \quad$ Fractal dimension of pore size distribution (-)

Selçuk Erol

selcuk.erol@vito.be 
$D_{\mathrm{ff}} \quad$ Fractal dimension of fracture network distribution (-)

$D_{\mathrm{R}} \quad$ Real dimension (-)

$h \quad$ Height of a hydraulic aperture (m)

$k_{\mathrm{i} 25} \quad$ Kinetic rate constant at $25^{\circ} \mathrm{C}\left(\mathrm{mol} \mathrm{m}^{-2} \mathrm{~s}^{-1}\right)$

$n \quad$ Power-law empirical exponent (-)

$p \quad$ Empirical constant (-)

$P \quad$ Pressure $(\mathrm{Pa})$

$R \quad$ Mineral dissolution/precipitation rate $\left(\mathrm{mol} \mathrm{m}^{-3} \mathrm{~s}^{-1}\right)$

$R S A \quad$ Reactive surface area $\left(\mathrm{m}^{2} \mathrm{~kg}^{-1}\right)$

$q \quad$ Empirical constant (-)

$r \quad$ Crystal radius (m)

$S \quad$ Specific surface area $\left(\mathrm{m}^{-1}\right)$

$S A \quad$ Surface area $\left(\mathrm{m}^{2}\right)$

$t \quad$ Time (s)

TR TOUGHREACT

$v \quad$ Mineral molar volume $\left(\mathrm{m}^{3} \mathrm{~mol}^{-1}\right)$

$V_{\mathrm{f}} \quad$ Volume fraction (-)

w Hydraulic aperture width (m)

\section{Greek Symbols}

$\kappa \quad$ Permeability $\left(\mathrm{m}^{2}\right)$

$\lambda \quad$ Surface roughness factor (-)

$\mu \quad$ Fluid dynamic viscosity (Pa s)

$\rho \quad$ Fluid density $\left(\mathrm{kg} \mathrm{m}^{-3}\right)$

$\tau \quad$ Tortuosity $(-)$

$\phi_{\mathrm{m}} \quad$ Matrix porosity (-)

$\phi_{\mathrm{f}} \quad$ Fracture porosity (-)

$\Omega \quad$ Mineral saturation index (-)

\section{Subscripts}

$0 \quad$ Initial

c Critical

f Fracture

geo Geometric

$\mathrm{i} \quad i$ th mineral

m Matrix

min Variable minimum

max Variable maximum

TOT Total

\section{Introduction}

Government climate and energy policies increasingly emphasize development of renewable energy resources (EGEC 2018). Heat stored and generated within the Earth (geothermal energy) shows high potential in this regard as it is stable on human timescales, accessible from any country - even where there is no volcanic or hydrothermal activity, and sufficient to meet worldwide energy demands. The total heat flux through the Earth's surface 
is $44 \mathrm{TW}$, equivalent to $1.400 \mathrm{EJ}$ per year. This is approximately three times greater than annual worldwide energy usage (British Petroleum Global 2015). Another advantage is low greenhouse gas emissions (Antics and Sanner 2007; Gallup 2009). Economic feasibility poses a barrier to further development, however. It is possible to generate electricity from fluid extracted at temperatures as low as $75-130{ }^{\circ} \mathrm{C}$, associated with reservoirs at depths of approximately $2500-4000 \mathrm{~m}$ under an ambient geothermal gradient of $0.033{ }^{\circ} \mathrm{C}$ $\mathrm{m}^{-1}$ (Idaho National Laboratory 1174), but cheaper and more efficient where fluid temperatures are higher. New drilling projects increasingly use techniques such as laser-jet drilling and electro-impulse technology (Richter 2017) to target depths of $\geq 3000 \mathrm{~m}$ with the goal of accessing higher temperatures. However, the cost of drilling and reservoir construction at greater depth (higher temperature) is high. The first commercial-scale test of a deep geothermal system is in progress at Soultz-sous-Forêts, France. As fluid introduced at the surface circulates through artificially fractured granite at depths of 3500-5000 m, its temperature increases to $\sim 155{ }^{\circ} \mathrm{C}$. The heated fluid feeds an Organic Rankine Cycle installation with a net electric output of $1.5 \mathrm{MW}$ and is subsequently injected back into the reservoir at a temperature of $\sim 60{ }^{\circ} \mathrm{C}$. Such a deep reservoir (Balmatt) has recently been constructed within the Carboniferous Limestone Group near the town of Mol in the Campine area of Belgium. The production well, MOL-GT-01, reaches the reservoir at a depth of $3610 \mathrm{~m}$; the injection well, MOL-GT-02, achieves a depth of $4600 \mathrm{~m}$. Measured production temperatures are sufficient to match local heat and power demand. Expected gross power output is up to $48 \mathrm{MW}$ by 2020 with a flow rate of $140 \mathrm{~m}^{3} \mathrm{~h}^{-1}$ (Laenen et al. 2014). In addition to cost, another major concern for these and other such reservoirs relates to the long-term stability of production, which is not guaranteed. Porosity-permeability evolution over time within geothermal reservoirs and in installations can have a significant impact on system sustainability. Porosity and permeability changes arise from gradients in temperature, pressure, and composition that drive reactions associated with mineral dissolution or precipitation (Satman et al. 1999; Şimşek et al. 2005; Thorhallsson 2005; Akın 2012). Permeability controls the duration and location of fluid flow, thereby determining fluid production and temperature at the surface. However, characterizing permeability evolution is not straightforward.

This study presents a predictive analytical algorithm of dual porosity coupled with mineral precipitation and dissolution. Mineral saturation indices, kinetic rate laws, and consequently, permeability, evolve during fluid-rock interaction. An application case uses mineral saturation indices from TOUGHREACT, a widely used reactive transport code (Xu et al. 2011). The dissolution rate constants are taken from Palandri and Kharaka (2004). Fitting of the novel algorithm is based on comparison of algorithm predictions with results from laboratory flow-through experiments, where permeability was measured following fluid circulation through natural rock samples. In the experiments, fluid and rock temperatures varied from 40 to $100{ }^{\circ} \mathrm{C}$, pressure ranged from 5 to $30 \mathrm{MPa}$, fluid was saline (ionic strength, $\left.3 \mathrm{~mol} \mathrm{~kg}^{-1}\right)$ and $\mathrm{CO}_{2}$-bearing $\left(0.2 \mathrm{~mol} \mathrm{~kg}^{-1}\right)$, and lithologies included limestone and dolomite, relevant to the Campine Basin, Belgium. Porosity, hydraulic aperture dimensions, and permeability were measured using in situ X-ray micro-computer tomography (CT) during flow. Evolving fluid chemistry was measured during flow via inductively coupled plasma-optical emission spectrometry (ICP-OES). The samples represent drill cores of carboniferous limestone and dolomite from the Turnhout and Halen geothermal wells. The wells exploit an identical geothermal reservoir in the Campine Basin, Belgium (Petitclerc et al. 2016). Understanding permeability evolution during fluid circulation at these wells will be useful for predicting their future performance and that of the nearby, recently drilled Balmatt reservoir. 
Next is a comparison of porosity, permeability, and reactive surface area predictions based on the novel algorithm with output from TOUGHREACT simulations. TOUGHREACT simulations, consisting of small-scale flow and mineral dissolution/precipitation, were performed via the PetraSIM interface (PetraSIM 2017). All simulations used geochemical data from the Balmatt reservoir and the experimental measurements of reactive surface area, matrix, and fracture porosity. The power-law (Civan 2001), Kozeny-Carman (Carman 1939), and Verma and Pruess (1988) equations are available for predicting permeability in TOUGHREACT. These methods use empirical exponents that are not tied to the system of interest because they require existing data from the literature for definition. Our opinion is that our approach uses parameters that are more straightforward to measure. In some situations, it may provide an advantage in terms of computation time compared to existing numerical techniques implemented in TOUGHREACT and other reactive transport codes, such as OpenGeoSys (Kolditz et al. 2012) and HydroGeoChem (Yeh et al. 2004).

We also compared algorithm results with laboratory data (reactive surface area, porosity, and permeability measurements) from Smith et al. (2013, 2017), obtained from flowthrough experiments designed to simulate fluid circulation and interaction with surrounding rocks within a reservoir. The comparison is favorable.

\subsection{Challenges of Characterizing Permeability Evolution}

Reactive transport models are increasingly popular for predicting the long-term evolution, performance, and lifetimes of geothermal reservoirs (Steefel and Van Cappellen 1990; Appelo and Postma 2005; Steefel et al. 2005; Xu et al. 2014; Menke et al. 2016; Wang et al. 2016). However, they rely on published thermodynamic and kinetic databases that span limited ranges of temperature, pressure, and composition compared to natural systems. A particular challenge with regard to deep geothermal systems is that fluid is often saline $\left(\mathrm{NaCl}>3 \mathrm{~mol} \mathrm{~kg}^{-1}\right)$ with high dissolved gas concentrations $\left(>0.1 \mathrm{~mol} \mathrm{~kg}^{-1}\right.$ of $\mathrm{CO}_{2}$, $\mathrm{N}_{2}$, and $\mathrm{CH}_{4}$ ). Rocks can consist of various mineral types, including solid solutions. This compositional diversity can influence the nature and rates of mineral dissolution and precipitation reactions. Also, the data generally correspond to average values measured over rock volumes, which may not accurately reflect pore scale processes (Gouze and Luquot 2011; Menke et al. 2015; Noiriel and Daval 2017). Noiriel et al. (2009) made an interesting contribution in this regard. They evaluated competing representations of pore reactive surface area on permeability evolution during dissolution: a grain-pore model based on both spherical grains and pores that decrease in size versus a sugar-lump model in which the porous medium comprises a cluster of spherical grains that dissociate as dissolution of each grain progresses (similar to sugar dissolving in a cup of coffee). The sugar-lump model provided the best fit to reactive surface area data measured from laboratory flowthrough experiments and a natural system. However, the model used predefined empirical coefficients similar to the power-law permeability models. This issue is discussed further below.

TOUGHREACT is one of the most widely used reactive transport models (Xu et al. 2008, 2011). It uses the MINC (Multiple Interacting Continua) approach for modeling flow in fractured and porous media. MINC is a generalization of the classic double-porosity concept developed by Warren and Root (1963). There are several options for defining rock matrix/fracture connections. Matrix sub-gridding is used to resolve property gradients. 
There are a number of permeability models, such as Kozeny-Carman (Carman 1939), Verma and Pruess (1988), and the cubic law (Steefel et al. 2005; Xu et al. 2008).

The cubic-law is essentially the power-law equation of Civan (2001) with an empirical exponent, $n$, fixed at "3" (Xu et al. 2008).

$$
\kappa(t)=\kappa_{0}\left(\frac{\phi(t)}{\phi_{0}}\right)^{n} \rightarrow \text { cubic-law }=\kappa(t)=\kappa_{0}\left(\frac{\phi(t)}{\phi_{0}}\right)^{3}
$$

Here, $\kappa_{0}$ is the initial permeability, $\phi_{0}$ is the initial fracture porosity, and $\phi$ is the porosity as a function of time, $t$. The power-law equation has been applied to calculate fracture permeability based on evolving porosity. Advantages include accounting for porosity change due to reactive flow and description of the dynamic variation of fracture permeability due to temperature. The value of $n$ corresponds to the slope of plotted logarithmic porosity versus permeability data. Permeability calculation based on the power-law equation therefore requires an a priori assumption about permeability in the rock type of interest. Values for $n$ are generally taken from published data-results from laboratory porosity measurements and permeability estimates based on flow-through experiments and X-ray micro-CT (Luhmann et al. 2014; Menke et al. 2016). The majority of such experiments have been performed on sedimentary rock types (e.g., limestone, dolomite, and sandstone). Several authors have proposed that-consistent with TOUGHREACT $-n$ is constant for particular rock types, such as limestone and dolomite (Luquot and Gouze 2009; Gouze and Luquot 2011; Luquot et al. 2014). However, Smith et al. (2013, 2017) disagree. They performed flow-through experiments that used various types of limestone and dolostone to evaluate $n$. They found that $n$ varies from 6 to 8 for heterogeneous limestone, 1.6-3.3 for heterogeneous dolostone, and 2.5-8 for homogeneous dolostone. These values differ from the value of 3 assigned in TOUGHREACT. Also, several authors have observed that $n$ can also be a function of fluid composition. For example, $\mathrm{CO}_{2}$ can influence fluid-rock interaction within limestone, dolomite, and sandstone systems, either where added alone (Noiriel et al. 2004; Luhmann et al. 2012, 2014; Hao et al. 2013; Tutolo et al. 2014, 2015; Huq et al. 2015; Soong et al. 2016; Smith et al. 2017) or as $\mathrm{CO}_{2}$-saturated brine (Kong et al. 2016; Wang et al. 2016; Orywall et al. 2017).

The simplified Kozeny-Carman equation (Carman 1939; Bear 1972) is mostly used to evaluate matrix permeability.

$$
\kappa(t)=\kappa_{0} \frac{\left(1-\phi_{0}\right)^{2}}{(1-\phi(t))^{2}}\left(\frac{\phi(t)}{\phi_{0}}\right)^{3}
$$

The power-law and Kozeny-Carman equations do not address pore/fracture size or geometric variations, pore connectivity, or tortuosity. Natural pore channels may vary in diameter, important because of a potential impact on flow. Mineral precipitation or dissolution may change pore size and clog or widen pore throats, leading to changes in porosity or pore connectivity (Verma and Pruess 1988). Even modest variations in porosity can impact permeability significantly (Vaughan 1987; Pape et al. 1999). Verma and Pruess (1988) formulated a porosity-permeability model aimed at a more sensitive coupling of permeability to porosity, where a "critical" porosity is associated with zero permeability. The critical porosity is a percolation threshold value below which the pore network is unconnected at the scale of the sample. 


$$
\kappa(t)=\kappa_{0}\left(\frac{\phi(t)-\phi_{c}}{\phi_{0}-\phi_{c}}\right)^{n}
$$

Here, $\phi_{\mathrm{c}}$ is the critical porosity and $n$ is a power-law exponent that is subject to the same limitations discussed above in relation to the cubic-law/power-law equation implemented in TOUGHREACT. The parameters are both medium-dependent.

\section{Flow-Through Laboratory Experiments}

Flow-through laboratory experiments were performed at Geothermal International Centre (GZB) in Bochum, Germany. The flow-through apparatus consisted of three pumps, an autoclave that contained the rock plugs, a heating jacket, and one reactor connected both to the $\mathrm{CO}_{2}$ gas tank and to the pumps (Fig. 1a). We used a CT scanner manufactured by ProCon X-ray based on their CT-Alpha model (Fig. 1b) to image at very fine scale (i.e., $8-12 \mu \mathrm{m}$ ) the internal structure of rock samples in three dimensions during flow. This micro-CT imaging was performed under various confining pressures, $P_{c o n}$, during fluid circulation to determine the hydraulic aperture heights and fracture porosities of rock samples. We sampled reactive fluid during the flow-through tests. Each fluid sample was diluted with nitric acid $\left(\mathrm{HNO}_{3}\right)$ to stabilize the fluid against mineral precipitation. We used an ICP-OES Optima 8300 (PerkinElmer 2010; Stefan and Neubauer 2014) to measure the chemistry (element compositions) of the reactive fluid. These data were used in

(a)

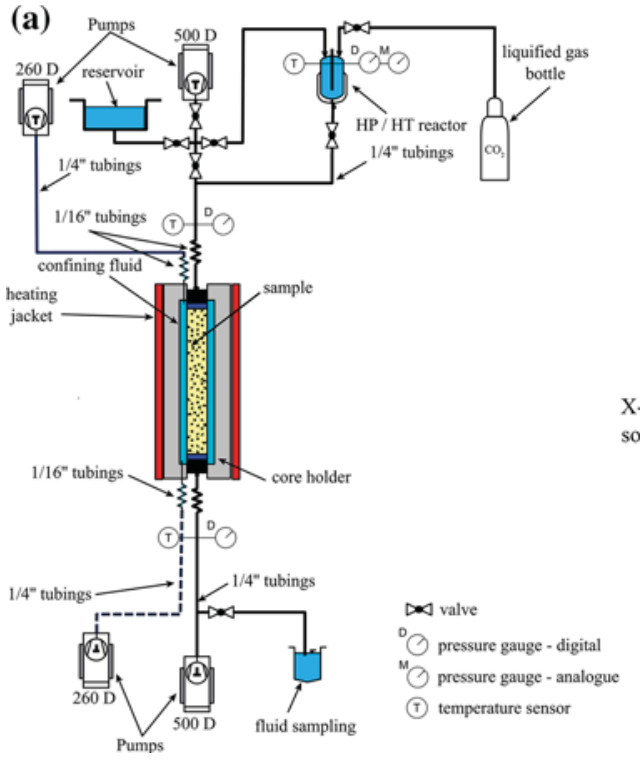

(b)

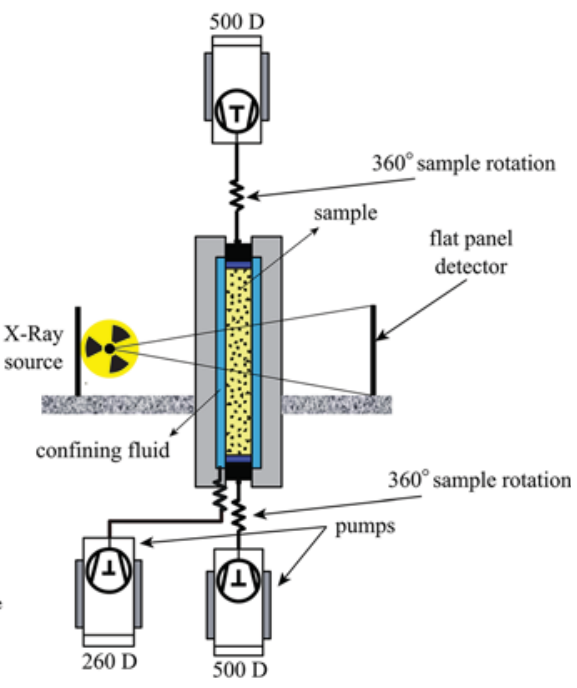

Fig. 1 a The flow-through experimental apparatus (cross section). Fluid enters at the bottom of the tube and flows upwards. Flow rate was measured with a TELEDYNE ISCO D-series device. b Micro-CT scanning during flow-through experiments to measure hydraulic fracture size under confining pressure corresponding to $5-30 \mathrm{MPa}$ 
benchmarking our reactive transport simulations. Details of the experimental setup are further explained in "Appendix A."

\subsection{Sample Selection and Core Preparation}

The flow-through experiments used dolomite and limestone from the Halen and Turnhout boreholes (Fig. 2a), respectively, within the Campine Basin, Belgium. The limestone and dolomite are similar to those from the nearby Balmatt reservoir in terms of major element chemistry, mineral types, and their relative proportions (Laenen 2003). Dolomite was collected at depths of $1200 \mathrm{~m}, 1313 \mathrm{~m}, 1365 \mathrm{~m}$, and $1366 \mathrm{~m}$. Limestone was obtained at depths of $2188 \mathrm{~m}, 2189 \mathrm{~m}$, and $2355 \mathrm{~m}$. Brine was obtained from the Balmatt well (Fig. 2b).

Limestone in the Turnhout area is crystalline, bioclastic, and of Late Visian age. It formed on a shallow shelf during slow subsidence (Muchez et al. 1991). Most samples have minor fissures and veins filled with calcite that likely acts to impede fluid flow. Overall, connected porosity is less than $1 \%$. Dolomite has organic-rich intervals and silicified levels in the Halen area (Laenen 2003). Micro-CT images demonstrate the existence of large, unconnected pores.

The mineralogical composition of the samples were determined by X-ray diffraction (XRD). The details of XRD measurements can be found in Appendix A. For the Halen samples, only dolomite was detected. The limestone samples obtained from the Turnhout borehole are composed of $97 \%$ calcite and $<3 \%$ dolomite and quartz (the sum of the measured components is $100 \%$ ). Thin section analysis shows that the studied limestone sample mostly consists of a cemented packstone-grainstone with bioclast fragments (Fig. 3c).

The samples were fractured via application of uniaxial force, and the broken pieces were then glued together (Fig. 3a). Six smaller cores of limestone and six of dolomite, each $2.3 \mathrm{~cm}$ long and $1.0 \mathrm{~cm}$ in diameter, were then drilled to preserve the aperture and polished. After polishing, the samples were submerged in acetone for 1 day to dissolve the glue in the aperture.

(a)

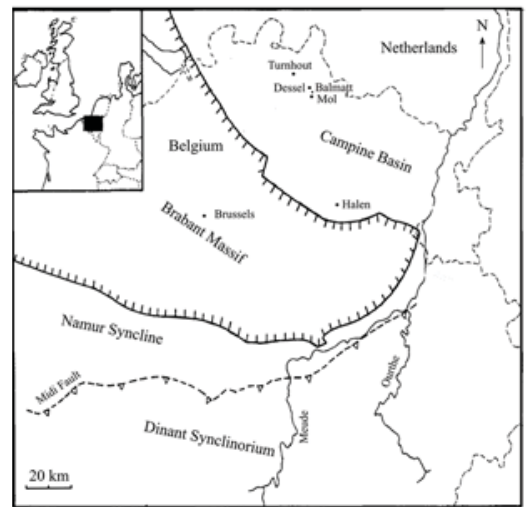

(b)

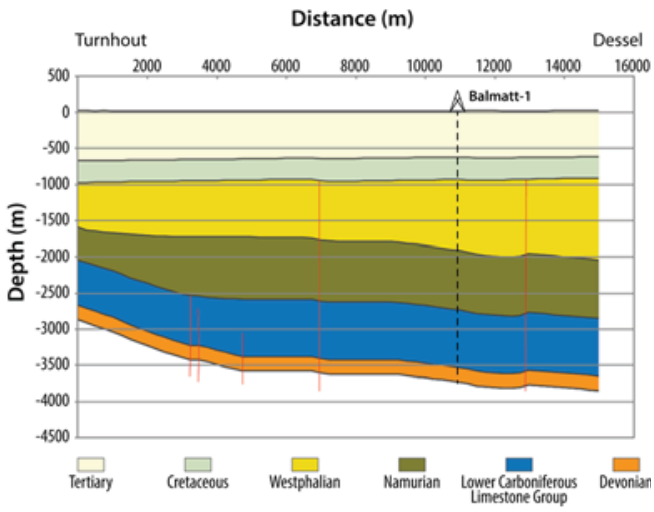

Fig. 2 a Location of the Campine Basin and Halen and Turnhout boreholes in northern Belgium (modified after Muchez et al. 1991). b Geological setting of the geothermal reservoir with the location of the first well at the Balmatt site (Laenen et al. 2014). The vertical red lines depict faults 
(a)

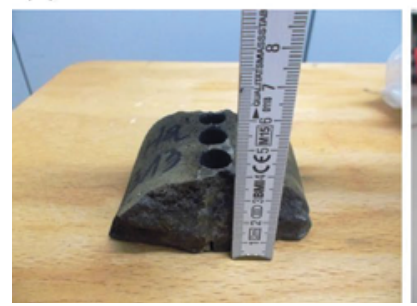

(b)

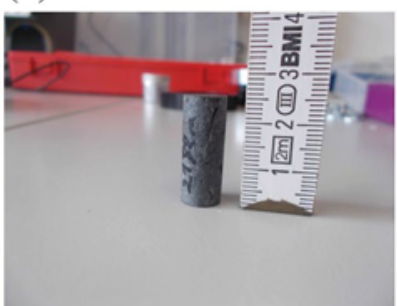

(c)

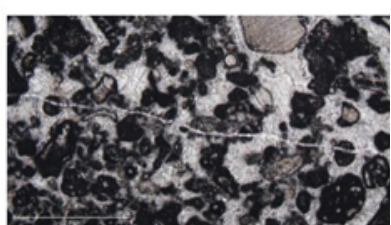

Fig. 3 Preparation of dolomite and limestone samples where each sample had low matrix permeability and was bisected by an aperture to simulate fracturing. a Glued and drilled dolomite sample (Halen, $1200 \mathrm{~m}$ depth). b Prepared limestone sample showing a roughly horizontal aperture in the middle (Turnhout $2188 \mathrm{~m})$. c Thin section of the Turnhout limestone sample

\subsection{Natural Brine}

Two pressurized brine samples were extracted at depths of $3280 \mathrm{~m}$ and $3400 \mathrm{~m}$ from well Mol-GT-01. Gas and chemical aqueous species were determined in the laboratory (Seibt 2016). The two brines had nearly identical compositions (Table 1). Measured $\mathrm{pH}$ was $~ 5.4$ and the amount of dissolved $\mathrm{CO}_{2}$ was $\sim 0.2 \mathrm{~mol} \mathrm{~kg}^{-1}$ at $120{ }^{\circ} \mathrm{C}$ under $35 \mathrm{MPa}$ confining pressure.

$\mathrm{Sr}^{2+}$ and $\mathrm{Ba}^{2+}$ can typically substitute into carbonate lattices, but have minor impact on mineral volumes and therefore have minimal influence porosity and permeability. We

Table 1 Composition of the brine collected from the Balmatt reservoir

\begin{tabular}{|c|c|c|}
\hline \multirow[t]{2}{*}{ Chemical species } & \multicolumn{2}{|c|}{ Concentration $\left(\mathrm{mol} \mathrm{kg}^{-1}\right)$} \\
\hline & $(3400 \mathrm{~m})$ & $(3280 \mathrm{~m})$ \\
\hline \multicolumn{3}{|l|}{ Cations } \\
\hline Sodium $\left(\mathrm{Na}^{+}\right)$ & 2.1652 & 2.1565 \\
\hline Potassium $\left(\mathrm{K}^{+}\right)$ & 0.071 & 0.0736 \\
\hline Calcium $\left(\mathrm{Ca}^{2+}\right)$ & 0.229 & 0.2283 \\
\hline Magnesium $\left(\mathrm{Mg}^{2+}\right)$ & 0.0229 & 0.023 \\
\hline Strontium $\left(\mathrm{Sr}^{2+}\right)$ & 0.0045 & 0.0046 \\
\hline $\operatorname{Barium}\left(\mathrm{Ba}^{2+}\right)$ & $1.2234 \times 10^{-4}$ & $1.2015 \times 10^{-4}$ \\
\hline Iron $\left(\mathrm{Fe}^{2+}\right)$ & 0.0145 & 0.0144 \\
\hline Manganese $\left(\mathrm{Mn}^{2+}\right)$ & $2.54 \times 10^{-4}$ & $2.476 \times 10^{-4}$ \\
\hline Ammonium $\left(\mathrm{NH}^{4+}\right)$ & 0.0148 & 0.0139 \\
\hline \multicolumn{3}{|l|}{ Anions } \\
\hline Chloride $\left(\mathrm{Cl}^{-}\right)$ & 2.767 & 2.8263 \\
\hline Hydrogen carbonate $\left(\mathrm{HCO}_{3}^{-}\right)$ & 0.0183 & 0.0185 \\
\hline Sulfate $\left(\mathrm{SO}_{4}{ }^{2-}\right)$ & 0.0034 & 0.004 \\
\hline Bromide $\left(\mathrm{Br}^{-}\right)$ & 0.0019 & 0.0017 \\
\hline \multicolumn{3}{|l|}{ Other parameters } \\
\hline Silicon $(\mathrm{Si})$ & 0.0017 & 0.0017 \\
\hline $\mathrm{SiO}_{2}$ & 0.0017 & 0.0017 \\
\hline $\mathrm{H}_{2} \mathrm{SiO}_{3}$ & 0.0017 & 0.0017 \\
\hline
\end{tabular}


observed few silica-bearing minerals and no iron-bearing minerals in the limestone and dolomite samples. On this basis, the flow-through experiments used a synthetic brine that excluded minor species $\left(\mathrm{Fe}^{2+}, \mathrm{SiO}_{2}, \mathrm{Sr}^{2+}, \mathrm{Br}^{-}, \mathrm{Ba}^{2+}\right.$, and $\left.\mathrm{NH}^{4+}\right)$ and gas (methane and nitrogen). Simplification of the chemical system allowed us to focus on the bulk of the system and dominant reactions.

\section{Analytical Algorithm for Reactive Transport Modeling to Evaluate Dual Porosity and Permeability}

Here, we describe an algorithm that extends the existing analytical model of Erol et al. (2017) for calculating porosity-permeability in porous and fractured media to reactive (transient) conditions. Published kinetic rate laws (Lasaga 1984) provide rates of change for mineral volume fraction, porosity, crystal radius, and hydraulic aperture dimension during reaction. We estimate the specific surface areas of fracture and porous matrix pore connections based on a fractal approach. Evaluation of permeability and porosity variation is based on an iterative calculation. Figure 4 illustrates the workflow. The mathematical derivations presented below are elucidated in Appendix B.

The first step (i) is calculation of the fractal dimensions of porous and fractured media. Next (ii) is calculation of the specific surface areas of rock constituent minerals with regard to their volume fractions. This is for the purpose of describing pore and fracture network distributions. The third step (iii) involves calculation of the kinetic rates of dissolution/ precipitation for each mineral with respect to mineral saturation indices obtained from TOUGHREACT. As the reaction rates are calculated, the volume fractions of minerals (and therefore porosity) change. Changes in crystal radii and hydraulic aperture heights are also evaluated. These calculation steps are carried out iteratively for each mineral at a particular time step. The final task at a given time step is calculation of permeability with respect to the rate of change in fracture and matrix porosity, hydraulic aperture height, and pore radius.

The analytical algorithm presented step-by-step below relates to Fig. 4. The subscripts $f$ and $m$ denote the fracture, and the matrix, respectively; $i$ refers to an individual mineral.

(i) Calculation of the fractal dimension of matrix blocks is based on Yu and $\mathrm{Li}$ (2001)

$$
D_{\mathrm{fm}}=D_{\mathrm{R}}-\ln \left(\frac{\phi_{\mathrm{m} 0}}{\frac{a_{\min }}{a_{\max }}}\right)
$$

where $D_{\mathrm{fm}}$ is the fractal dimension of the matrix blocks. The fractal dimension is a dimensionless parameter used to express the complexity of pore or fracture distribution in a medium. $D_{\mathrm{R}}$ is the problem dimension, taken as 3 (i.e., three-dimensional), $\phi_{\mathrm{m} 0}$ is the initial matrix porosity, and $a_{\min }$ and $a_{\max }$ are the minimum and maximum pore radii. Estimation of pore radius based on porosity and crystal diameter is outlined in Appendix B.

(ii) The specific surface area of each constituent mineral of rock in matrix blocks is calculated with regard to its volume fraction $\left(V f_{\mathrm{mi}}\right)$ and the surface roughness factor $\left(\lambda_{\mathrm{m}}\right)$ as

$$
S_{\mathrm{mi}}(t)=\lambda_{\mathrm{m}} \frac{3\left(r_{i \_ \text {min }}^{3} r_{i_{\_} \mathrm{max}}^{D_{\mathrm{fm}}}-r_{i \_ \text {min }}^{D_{\mathrm{fm}}} r_{i \_ \text {max }}^{3}\right)\left(D_{\mathrm{fm}}-4\right)}{\left(r_{i \_ \text {min }}^{4} r_{i \_ \text {max }}^{D_{\mathrm{fm}}}-r_{i \_ \text {min }}^{D_{\mathrm{fm}}} r_{i \_ \text {max }}^{4}\right)\left(D_{\mathrm{fm}}-3\right)} V f_{\mathrm{mi}}(t)
$$




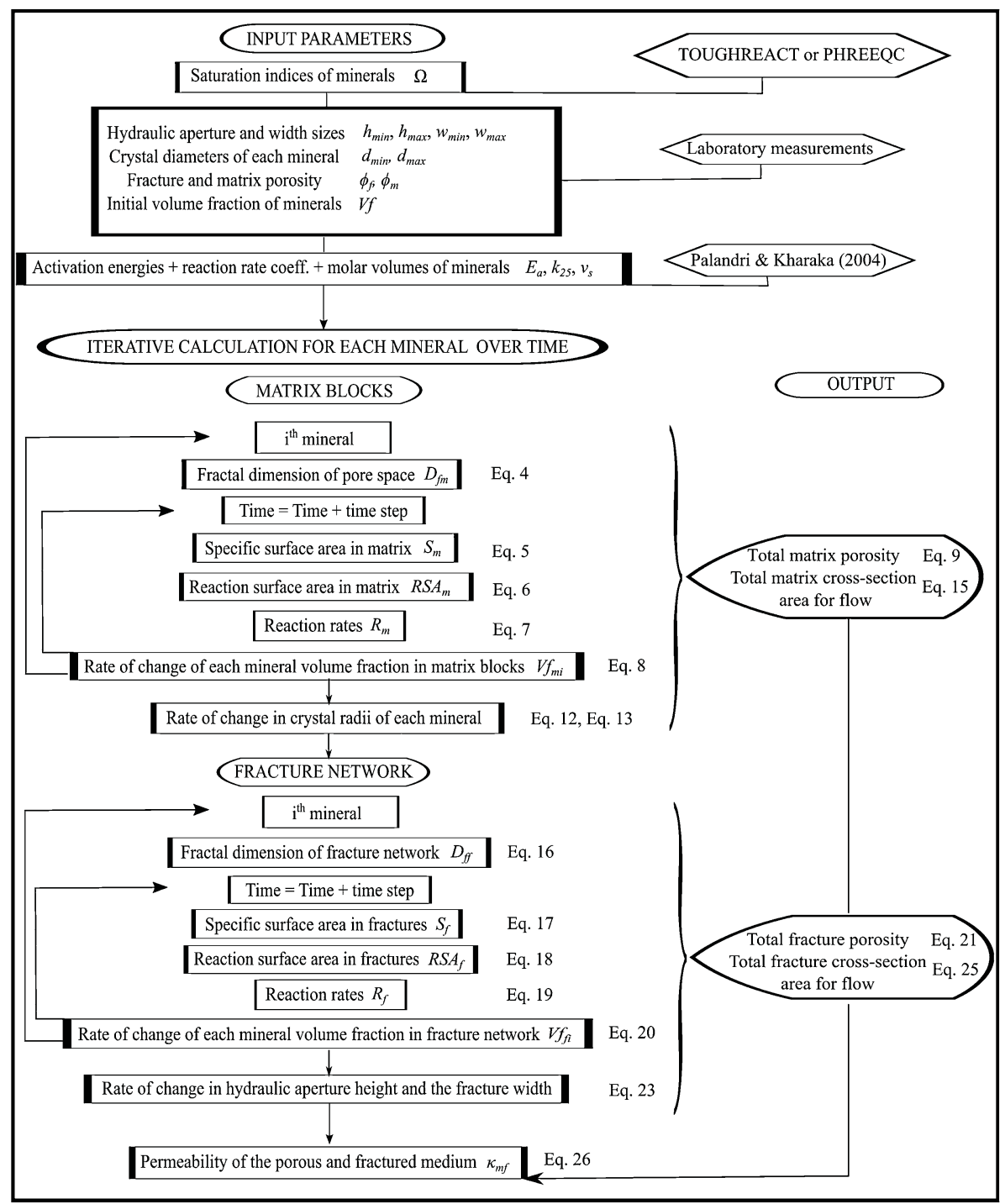

Fig. 4 Analytical model application workflow

where $\lambda_{\mathrm{m}}$ is the surface roughness factor and $r_{\min }$ and $r_{\max }$ are the minimum and maximum crystal radii. The mean value of the cumulative distribution can be set as the maximum value of a crystal radius. The surface roughness factor is the ratio between the total surface area and the geometric surface area. It has an impact on mineral dissolution rates because it influences flow and transport rates and masses (Noiriel et al. 2012). Since the flow regime is laminar for our reactive transport simulations, the surface roughness factor is set to one (Deng et al. 2018).

The reactive surface area can then be calculated for each mineral as shown in the TOUGHREACT v1.2 manual (Xu et al. 2008) for mass-based units of $\mathrm{m}^{2} \mathrm{~kg}^{-1}$ 


$$
R S A_{\mathrm{mi}}(t)=\frac{S_{\mathrm{mi}}(t)}{\rho_{\mathrm{w}} \phi_{\mathrm{m} 0}}
$$

where $\rho_{\mathrm{w}}$ is pure water density $\left(1000 \mathrm{~kg} \mathrm{~m}^{-3}\right)$ at $4{ }^{\circ} \mathrm{C}$ and $\phi_{\mathrm{m} 0}$ is the initial matrix porosity.

(iii) The kinetic rates of dissolution/precipitation for each mineral are calculated with respect to mineral saturation indices, $\Omega$, taken from TOUGHREACT. The kinetic rate equation that governs matrix pore radii for dissolution or precipitation is given by Lasaga (1984) as follows

$$
R_{\mathrm{mi}}(t)=\left.S_{\mathrm{mi}}(t) k_{i 25} \exp \left(\frac{-E_{i \_a 0}}{R_{\text {gas }}}\left[\frac{1}{T}-\frac{1}{298.15}\right]\right)|1-\overbrace{\left(\frac{\text { IAP }}{K}\right)}^{\Omega}|^{p}\right|^{q}
$$

in which $S_{\mathrm{mi}}$ is the specific surface area of the total pore space in the domain, $k_{\mathrm{i} 25}$ is the kinetic rate constant of each mineral at $25^{\circ} \mathrm{C}$, IAP is the ion activity product, and $\mathrm{K}$ is the equilibrium constant. IAP $=\mathrm{K}$ implies equilibrium of a mineral phase, IAP $<\mathrm{K}$ implies dissolution, and IAP $>\mathrm{K}$ indicates precipitation. The ratio of IAP to $\mathrm{K}$ is the saturation index of a mineral. The parameters $p$ and $q$ are empirical and dimensionless constants related to dissolution/precipitation and are generally designated as one for limestone and dolomite dissolution (Palandri and Kharaka 2004).

As reaction rates are calculated, the volume fraction change in each mineral is also calculated. The volume fractions are then summed to yield the total porosity change (Emmanuel and Berkowitz 2007)

$$
V f_{\mathrm{mi}}(t)=V f_{\mathrm{mi0}} \pm v_{i} R_{\mathrm{mi}}(t) t
$$

where $v_{i}$ is the molar volume of each mineral. The \pm relates to dissolution or precipitation and $V f_{\text {mio }}$ is the initial volume fraction.

$$
\phi_{\mathrm{m}}(t)=1-\sum_{i=1}^{n} V f_{\mathrm{mi}}(t)-V f_{\mathrm{mnon}}
$$

in which $n$ is the number of minerals (e.g., three minerals, calcite, dolomite, and quartz), $V f_{\mathrm{mi}}$ is the volume fraction of mineral, and $V f_{\mathrm{mnon}}$ is the volume fraction of non-reactive rock.

The rate of change in crystal radius due to reaction can be calculated as

$$
r_{i \_g e o}(t)=\frac{\phi_{\mathrm{m} 0}}{S_{\mathrm{mi}}(t)}
$$

$r_{i \_ \text {geo }}$ corresponds to the geometric radii of minerals changing over time.

Changes in crystal radius for each mineral can be calculated with respect to mineral volume fraction $V f_{\mathrm{mi}}(t)$ as

$$
\begin{gathered}
\Delta r_{i}(t)=\frac{V f_{m i}(t)-V f_{\text {mi0 }}}{V f_{\text {mi0 }}} r_{i_{-} g e o}(t) \\
r_{i \_ \text {min }}(t)=r_{i \_ \text {min } 0} \pm \Delta r_{i}(t)
\end{gathered}
$$




$$
r_{i \_\max }(t)=r_{i \_\max 0} \pm \Delta r_{i}(t)
$$

The pore cross-sectional area of each mineral can be calculated with respect to the corresponding crystal radius from minimum to maximum and multiplied with the volume fraction of each mineral $V f_{\mathrm{mi}}$ in the matrix domain

$$
A_{\mathrm{mi}}(t)=\frac{\pi a_{\mathrm{min}}^{D_{\mathrm{E}}-D_{\mathrm{fm}}-1}(t) a_{\max }^{-D_{\mathrm{E}}}(t)\left(a_{\min }^{3}(t) a_{\mathrm{max}}^{D_{\mathrm{fm}}}(t)-a_{\mathrm{min}}^{D_{\mathrm{fm}}}(t) a_{\mathrm{max}}^{3}(t)\right)\left(D_{\mathrm{fm}}-1\right)}{\left(D_{\mathrm{fm}}-3\right) \phi_{\mathrm{m}}(t)} V f_{\mathrm{mi}}(t)
$$

The total pore cross-sectional area can be calculated by summing the cross-sectional areas of each adjacent mineral as

$$
A_{m_{-} \mathrm{TOT}}(t)=\sum_{i=1}^{n} A_{\mathrm{mi}}(t)
$$

Following an iterative calculation of the matrix block parameters over time, the next step calculates the fracture domain parameters based on a similar algorithm.

The fractal dimension of the fracture network can be estimated from Erol et al. (2017) as

$$
D_{\mathrm{ff}}=D_{\mathrm{R}}-\ln \left(\frac{\phi_{\mathrm{f} 0}}{\frac{w_{\min } h_{\min }}{w_{\max } h_{\max }}}\right)
$$

where $D_{\mathrm{ff}}$ is the fractal dimension of the fracture network, $D_{\mathrm{R}}$ is the problem dimension, again, taken as 3 (i.e., three-dimensional), $\phi_{\mathrm{f} 0}$ is the initial fracture porosity, and $h_{\min }, h_{\max }$ $w_{\min }$, and $w_{\max }$ are the minimum and maximum hydraulic aperture heights and widths, respectively.

The specific surface area of each constituent mineral in the fracture network of the rock can be approximated as

$$
\begin{aligned}
S_{\mathrm{fi}}(t)= & \lambda_{\mathrm{f}} \frac{2\left[-w_{\min }\left(\frac{w_{\max }}{w_{\min }}\right)^{D_{\mathrm{ff}}} h_{\mathrm{max}}^{2}+h_{\min }\left(-w_{\max }^{2}+w_{\min }\left(\frac{w_{\max }}{w_{\min }}\right)^{D_{\mathrm{ff}}}\left(w_{\min }+h_{\min }\right)\right)\left(\frac{h_{\max }}{h_{\min }}\right)^{D_{\mathrm{ff}}}\right]}{\left(w_{\max }^{2}-w_{\min }^{2}\left(\frac{w_{\max }}{w_{\min }}\right)^{D_{\mathrm{ff}}}\right)\left(h_{\max }^{2}-h_{\min }^{2}\left(\frac{h_{\max }}{h_{\min }}\right)^{D_{\mathrm{ff}}}\right)} \\
& \times \frac{\left(D_{\mathrm{ff}}-2\right)}{\left(D_{\mathrm{ff}}-1\right)} V f_{\mathrm{fi}}(t)
\end{aligned}
$$

where $\lambda_{\mathrm{f}}$ is the surface roughness factor in the fractures, set to one again with respect to the flow regime, $V f_{\text {fio }}$ is the volume fraction of each mineral in the fracture domain, assumed identical to the matrix blocks. The mathematical derivation of Eq. 17 can be found in Appendix B.

The reactive surface areas can again be calculated for each mineral in the fracture domain as shown in the TOUGHREACT v1.2 manual in units of $\mathrm{m}^{2} \mathrm{~kg}^{-1}$

$$
\operatorname{RSA}_{\mathrm{fi}}(t)=\frac{S_{\mathrm{fi}}(t)}{\rho_{\mathrm{w}} \phi_{\mathrm{f} 0}}
$$


where $\phi_{\mathrm{f} 0}$ is the initial fracture porosity.

In the following step, the kinetic rate equation for dissolution or precipitation is calculated for the fracture network as

$$
R_{\mathrm{fi}}(t)=S_{\mathrm{fi}}(t) k_{i 25} \exp \left(\frac{-E_{i \_a 0}}{R_{\mathrm{gas}}}\left[\frac{1}{T}-\frac{1}{298.15}\right]\right)\left|1-(\Omega)^{p}\right|^{q}
$$

in which $S_{\mathrm{fi}}$ is the specific surface area of each mineral in the fracture network and $k_{\mathrm{i} 25}$ is the kinetic rate constant of each mineral at $25^{\circ} \mathrm{C}$.

As the reaction rates are calculated, the volume fraction change in each mineral is similar to Eq. 8 (Emmanuel and Berkowitz 2007)

$$
V f_{\mathrm{fi}}(t)=V f_{\mathrm{fi} 0} \pm v_{i} R_{\mathrm{fi}}(t) t
$$

where $v_{i}$ is the molar volume of each mineral, subtraction or addition of the second term on the right-hand side is determined, respectively, by dissolution or precipitation, and $V f_{\text {fio }}$ is the initial volume fraction.

The total fracture porosity change is based on summation over all minerals. In the sum function, again, dissolution is associated with a minus sign and precipitation with a positive sign.

$$
\phi_{\mathrm{f}}(t)=1-\sum_{i=1}^{n} V f_{\mathrm{fi}}(t)-V f_{\text {fnon }}
$$

where $n$ is the number of minerals, $V f_{\mathrm{fi}}$ is the volume fraction of a mineral of interest, and $V f_{\text {fnon }}$ is the volume fraction of non-reactive rock.

The rate of change in the height of a hydraulic aperture is (Xu et al. 2008)

$$
\begin{gathered}
h_{i \_g e o}(t)=\frac{\phi_{\text {fi0 }}}{S_{\text {fi }}(t)} \\
\Delta h_{i}(t)=\frac{V f_{\text {fi }}(t)-V f_{\text {fi } 0}}{V f_{\text {fi } 0}} h_{i \_ \text {geo }}(t) \rightarrow h_{i \_ \text {min } / \text { max }}(t)=h_{i \_ \text {min } 0 / \text { max } 0} \pm \Delta h_{i}(t)
\end{gathered}
$$

The cross-sectional area of fractures of each mineral can be predicted with respect to minimum and maximum of the hydraulic aperture heights and widths as

$$
A_{\mathrm{fi}}(t)=\left(\frac{\phi_{\mathrm{fi}}(t)}{\phi_{\mathrm{fi}}}\right) \frac{\left(w_{\min }^{2}(t)-w_{\max }^{2}(t)\left(\frac{w_{\max }(t)}{w_{\min }(t)}\right)^{-D_{\mathrm{ff}}}\right)\left(h_{\min }^{2}(t)-h_{\max }^{2}(t)\left(\frac{h_{\max }(t)}{h_{\min }(t)}\right)^{-D_{\mathrm{ff}}}\right)\left(D_{\mathrm{ff}}-1\right)^{2}}{w_{\min }(t) h_{\min }(t)\left(D_{\mathrm{ff}}-2\right)^{2}} V f_{\mathrm{fi}}(t)
$$

where $V f_{\mathrm{fi}}$ is the volume fraction of each mineral in the fracture domain. The total fracture network can be calculated as a sum of the cross-sectional areas of each mineral as

$$
A_{f_{-} T O T}(t)=\sum_{i=1}^{n} A_{f i}(t)
$$

At a last step, permeability is calculated with respect to the rate of change in porosity as in Erol et al. (2017) 


$$
\kappa_{\mathrm{mf}}(t)=\frac{\phi_{\mathrm{f}}(t)}{\tau_{\mathrm{f}}}\left(\frac{\frac{A_{\mathrm{f}-\mathrm{TOT}}(t)}{\chi}+24 A_{\mathrm{m}_{-} \mathrm{TOT}}(t)}{24}\right)
$$

in which $\tau_{\mathrm{f}}$ is the tortuosity of the fracture network and $\chi$ denotes a constant that can be estimated approximately as $\chi=w_{\min } / h_{\text {min }}$.

\section{Fitting}

The main aim of the flow-through experiments is to determine initial values of reactive surface area, hydraulic aperture dimension, and porosity of natural samples under in situ conditions. In order to test and demonstrate the analytical algorithm, we compare results from it with those from permeability equations used in TOUGHREACT. We have defined five distinct scenarios (Table 2) for initial application of Eq. 26, where the goal is to evaluate the effect on permeability of interaction between highly saline artificial brine- $\mathrm{CO}_{2}$ and dolomite as well as limestone at distinct temperature and pressure conditions within a reservoir.

Our ultimate aim is to compare the fit of results from the numerical and analytical models with permeability measurements. Therefore, we have set a constant pressure gradient with respect to the height of the hydraulic aperture in the numerical and analytical models. Hydraulic aperture heights are slightly distinct for each laboratory experiment, meaning that flow rates and pressure gradients are also distinct (due mainly to the short lengths of the samples, flow does not become fully developed). The lower the pressure gradient, the more challenging it is to estimate permeability, which we calculate based on Darcy's law. We have investigated a range of temperatures and confining pressures for limestone and dolomite.

\section{TOUGHREACT Benchmark}

\subsection{Model Setup}

For the TOUGHREACT calculations, we configured a model domain similar to the laboratory experiments (Fig. 5). For the calculation of ion activities of minerals, we used the Pitzer model, appropriate for saline fluid ( $>2 \mathrm{~mol} \mathrm{~kg}^{-1}$ ionic strength). The spatial mesh discretization in the model is of 400 cells over a length of $10 \mathrm{~cm}$. Flow velocity is set constant at $1.33 \times 10^{-6} \mathrm{~kg} \mathrm{~s}^{-1}$.

\subsection{Geochemical Input Parameters}

Chemical interactions between fluid and surrounding rock can lead to changes in fluid chemistry and mineral dissolution and precipitation. In order to determine an initial concentration for individual primary species, required for TOUGHREACT, we calculated the evolution of brine geochemistry due to interaction of brine- $\mathrm{CO}_{2}$ gas (e.g., $0.2 \mathrm{~mol} \mathrm{~kg}{ }^{-1}$ ) with natural limestone and dolomite based on PHREEQC (Parkhurst and Appelo 2013). The primary species determined with PHREEQC are shown in Table 3 and were provided 


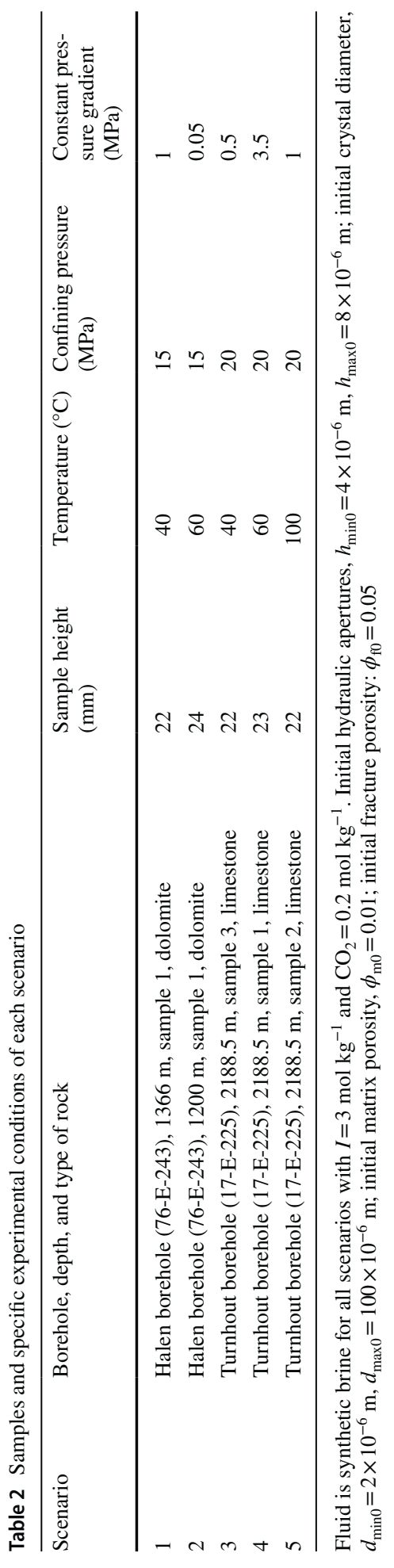




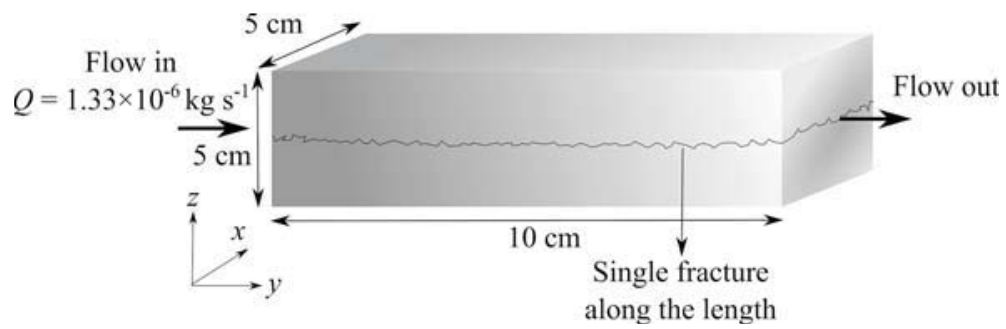

Fig. 5 Illustration of flow-through simulation in TOUGHREACT to serve as a basis of comparison with results from the novel analytical algorithm (1D constant flow in cross section)

Table 3 Chemical components of the brine- $\mathrm{CO}_{2}$ with limestone interaction at $25^{\circ} \mathrm{C}$

Table 4 Approximated volume fractions of minerals in rocks for TOUGHREACT and analytical algorithm calculations

\begin{tabular}{lll}
\hline Species & CGUESS $\left(\mathrm{mol} \mathrm{kg}^{-1}\right)$ & CTOT $\left(\mathrm{mol} \mathrm{kg}^{-1}\right)$ \\
\hline $\mathrm{Ca}^{2+}$ & 0.2196 & 0.229 \\
$\mathrm{CO}_{2}$ & 0.1606 & 0.2347 \\
$\mathrm{H}^{+}$(activity) & $6.0 \times 10^{-5}(\mathrm{pH} \sim 5.4)$ & $6.231 \times 10^{-5}(\mathrm{pH} \sim 5.4)$ \\
$\mathrm{H}_{2} \mathrm{O}$ & $1.0(\mathrm{~L})$ & $1.0(\mathrm{~L})$ \\
$\mathrm{HCO}_{3}^{-}$ & 0.001253 & 0.018306 \\
$\mathrm{Cl}^{-}$ & 2.76 & 2.767 \\
$\mathrm{~K}^{+}$ & 0.07 & 0.071 \\
$\mathrm{Na}^{+}$ & 2.157 & 2.165 \\
$\mathrm{Mg}^{2+}$ & 0.0175 & 0.0229 \\
$\mathrm{O}_{2}(\mathrm{aq})$ & $1.0 \times 10^{-6}$ & $1.0 \times 10^{-6}$ \\
\hline
\end{tabular}

The calculated ionic strength of the brine is $\sim 3 \mathrm{~mol} \mathrm{~kg}^{-1}$. CGUESS is an initial guess for the concentration of the individual primary species; CTOT is total moles of aqueous species

\begin{tabular}{lll}
\hline Sample & Mineral & Vol. fraction \\
\hline \multirow{2}{*}{ Limestone (turnhout borehole) } & Calcite & 0.90 \\
& Dolomite & 0.02 \\
Dolomite (Halen borehole) & Quartz & 0.02 \\
\hline
\end{tabular}

Total porosity both in limestone and dolomite samples is $6 \%$

as input in TOUGHREACT. As an input of a known $\mathrm{pH}$ value in TOUGHREACT, one can set $\mathrm{CTOT}=10^{-\mathrm{pH}}$ for $\mathrm{H}^{+}$activity and $\mathrm{H}_{2} \mathrm{O}$ to $1 \mathrm{~L}(\mathrm{CTOT}=1)$.

We estimated the initial volume fractions of limestone and dolomite from XRD quantitative data (Sect. 2.1). Regarding the XRD measurements, the mineral proportions were approximated with respect to the total sample volume for the calculation both in the analytical algorithm and TOUGHREACT simulation. The limestone sample (Turnhout) dominantly consists of calcite and small amount of dolomite and quartz. Therefore, we set the volume fraction of calcite at $\sim 90 \%$. Dolomite and quartz in limestone were set at $2 \%$ (Table 4). The dolomite (Halen) sample is pure (99\% dolomite endmember). The crystal 
diameters of minerals were set to $2 \mu \mathrm{m}$ in TOUGHREACT which also assumes a spherical geometry for the crystals.

The kinetic rate parameters of minerals were taken from a USGS Report by Palandri and Kharaka (2004) and are listed in Table 5. The kinetic rate of reactions over time was calculated as in Eq. 7 or 19.

\subsection{Initial and Boundary Conditions}

For the TOUGHREACT reactive transport simulation, we used the EOS 1 module (single-phase flow). The simulation time was 30 years, a typical lifetime of a fluid extraction system. We used the default Newton-Raphson scheme with a relative error criterion for convergence of $1 \times 10^{-5}$. The time step was adaptive, with the maximum time step set to 86,400 s (1 day).

\section{Results}

\subsection{Initial Measurements}

Several initial laboratory tests were conducted to determine the initial permeability and the related hydraulic aperture heights of dolomite and limestone samples. We scanned a single sample of limestone and dolomite at various confining pressures (e.g., $5 \mathrm{MPa}$ to $30 \mathrm{MPa}$ ) with micro-CT during flow-through experiments performed with water at $20{ }^{\circ} \mathrm{C}$.

According to the initial measurements, the height of fracture hydraulic apertures in the dolomite and limestone samples varies from $4 \times 10^{-6} \mathrm{~m}$ to $8 \times 10^{-6} \mathrm{~m}$ as can be seen in Table 6. Despite minor changes in the measured fracture permeabilities with increasing pressure load, we were able to quantify large changes in open void volume for these fracture systems by using X-ray micro-CT. The dolomitic sample represents a fracture with a few large contact areas. In contrast, the limestone is characterized by smaller and more equally distributed contact areas (Fig. 6).

Regarding the initial tests, we set the initial values of hydraulic aperture height as $h_{\text {min }}$ $4 \times 10^{-6} \mathrm{~m}$ and $h_{\max } 8 \times 10^{-6} \mathrm{~m}$ for the analytical model predictions. The crystal diameters

Table 5 Dissolution and precipitation data for minerals

\begin{tabular}{llll}
\hline Mineral & $\begin{array}{l}\text { Initial vol. } \\
\text { fraction }^{\mathrm{a}} \\
\left(V_{\text {mineral }} / V_{\text {solid }}\right)\end{array}$ & $\begin{array}{l}\text { Activation } \\
\text { energy } E_{\mathrm{a}} \mathrm{b}\end{array}$ & Rate constant $\mathrm{k}^{298 \mathrm{~K} \text { b }}$ \\
\hline Calcite & $1.0 \times 10^{-6}$ & 23.5 & $1.5 \times 10^{-6}$ \\
Dolomite & $1.0 \times 10^{-6}$ & 52.2 & $2.6 \times 10^{-8}$ \\
Quartz & $1.0 \times 10^{-6}$ & 87.7 & $3 \times 10^{-14}$ \\
Aragonite & $1.0 \times 10^{-6}$ & 23.5 & $1.5 \times 10^{-6}$ \\
Halite & $1.0 \times 10^{-6}$ & 7.4 & 0.8106 \\
Magnesite & $1.0 \times 10^{-6}$ & 23.5 & $6.5 \times 10^{-10}$ \\
\hline
\end{tabular}

${ }^{\text {a }}$ The initial volume fraction $\left(V_{\text {mineral }} / V_{\text {solid }}\right)$ is assumed for calculating initial effective surface area if a mineral is not present at the start of a simulation but precipitates as a new reaction product. If zero, the initial volume fraction is assumed to be $10^{-5}$

${ }^{\mathrm{b}}$ Used both for dissolution and precipitation of minerals 


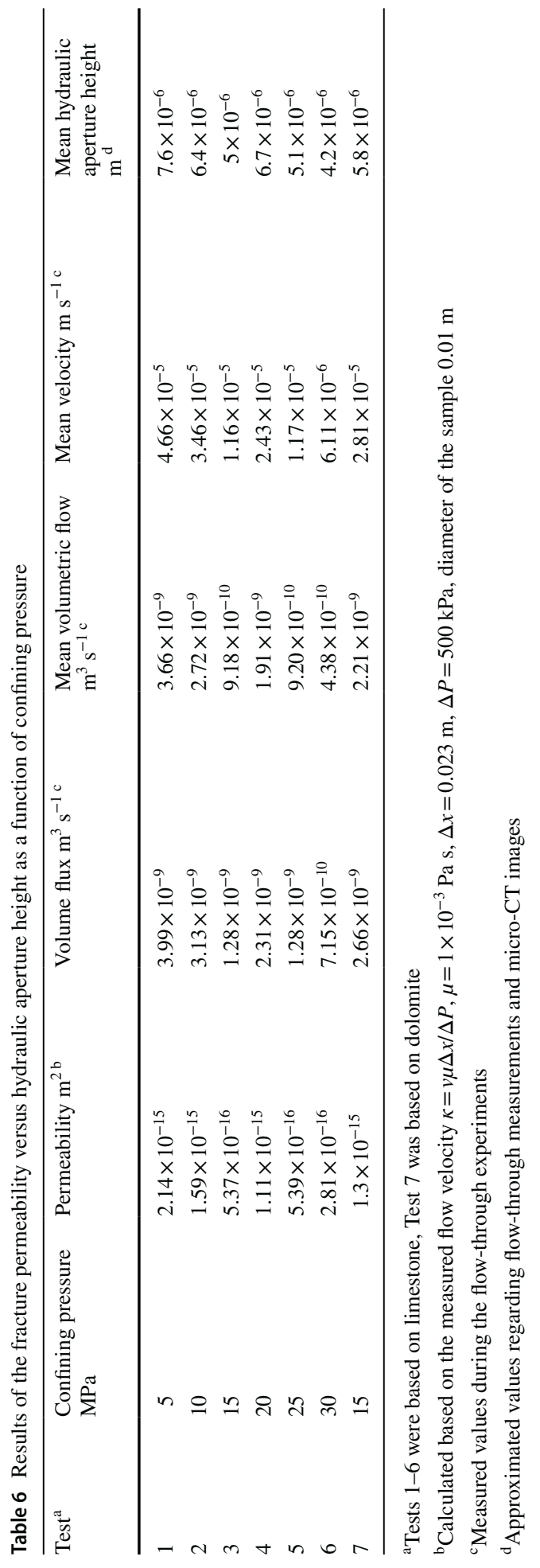


(a)

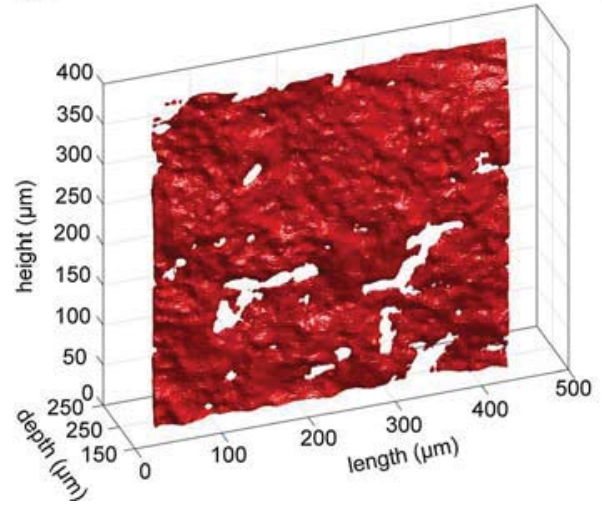

(b)

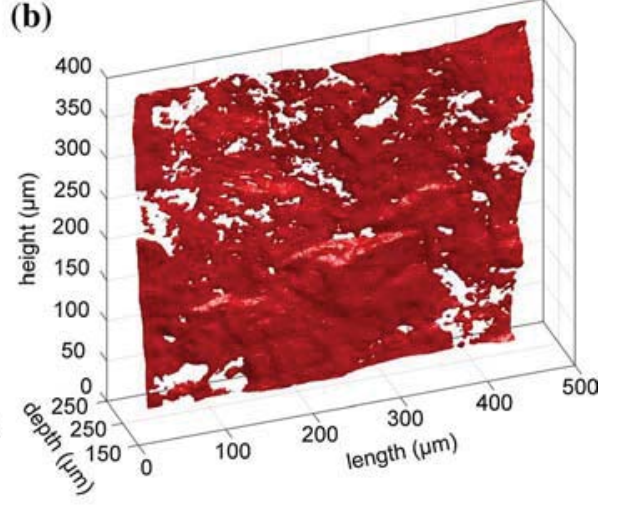

Fig. 6 3-D view of segmented fracture zone of $\mathbf{a}$ dolomite and $\mathbf{b}$ limestone at $5 \mathrm{MPa}$ confining pressure. Red colors indicate open pore space usable for fluid flow, while white colors represent contact areas

were set as $d_{\min } 2 \times 10^{-6} \mathrm{~m}$ and $d_{\max } 100 \times 10^{-6} \mathrm{~m}$ from thin section observations. These values provide similar initial permeability and porosity predictions compared to measurements. The measurements can be viewed as fitting of parameters within the analytical model to reproduce the permeability of experimental results. The measured initial permeability and fracture porosity of all limestone and dolomite samples range from $1 \times 10^{-15}$ to $5 \times 10^{-16} \mathrm{~m}^{2}$ and $5 \%$, respectively. TOUGHREACT requires specification of initial permeability and porosity. The initial fracture permeability in TOUGHREACT was set as the mean measured values (i.e., $2 \times 10^{-16} \mathrm{~m}^{2}$ ). In contrast, the analytical model predicts the permeability depending on the height of hydraulic aperture size estimated from flow-through experiment. Since the aperture width of the numerical model is $5 \mathrm{~cm}$, we set an identical value for the calculation of the analytical algorithm for all scenarios (i.e., $\left.w_{\min }=0.05 \mathrm{~m}, w_{\max }=0.0501 \mathrm{~m}\right)$.

\subsection{Application Case Results}

All flow-through experiments attained the target temperature within 1-2 $\mathrm{h}$. The evaluation of fracture permeability was calculated based on the temperature-dependent dynamic viscosity, taken from the reference tables according to salinity, temperature, and confining pressure (Phillips et al. 1980). During all flow-through experiments, the measured $\mathrm{pH}$ value did not change significantly over time. The measured $\mathrm{pH}$ value of the brine- $\mathrm{CO}_{2}$ fluid was approximately 5.2-5. This $\mathrm{pH}$ value is slightly lower than the initially measured $\mathrm{pH}$ value $(5.4 \mathrm{pH})$. The reason was that reactive fluid flowed only through the large single fracture, likely localizing interaction between the brine- $\mathrm{CO}_{2}$-rock and decreasing the saturation degree of the fluid.

For all TOUGHREACT simulations, the changes in porosity were not identical along the model domain (400 cells) and the rate of change in porosity was larger near the inlet. According to Noiriel et al. (2009), at a constant flow rate, the saturation index and the $\mathrm{pH}$ increase in fluid as reaction advances toward equilibrium and the dissolution rate of calcite constantly decreases along the flow path. This is why porosity change was larger close to the inlet. We compared the TOUGHREACT results at the inlet of the model (the saturation 

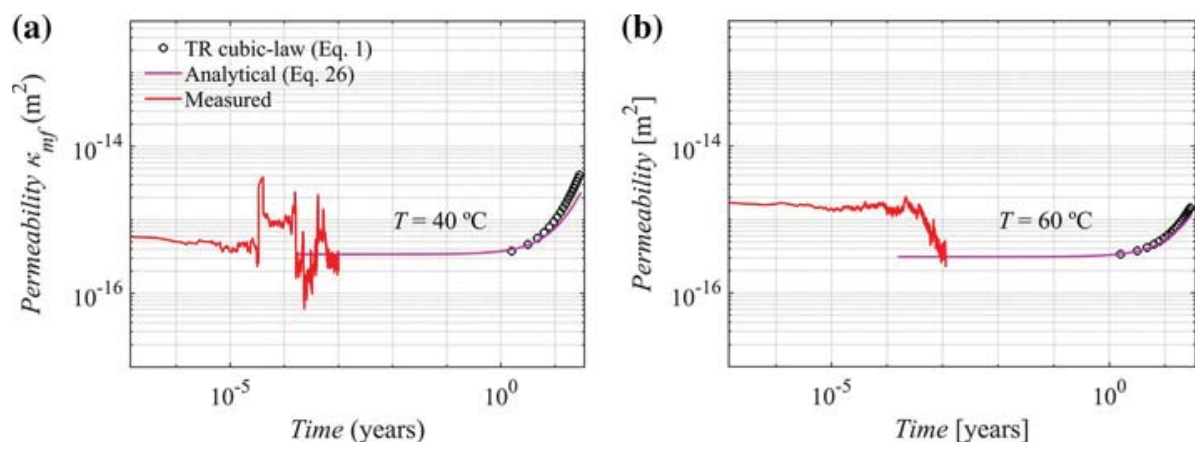

Fig. 7 Fracture permeability results of Halen borehole (76-E-243) dolomite samples: a Scenario 1, $1366 \mathrm{~m}$ at $40{ }^{\circ} \mathrm{C}$; b Scenario $2,1200 \mathrm{~m}$ at $60{ }^{\circ} \mathrm{C}$. TR: TOUGHREACT. RMSE between analytical versus flowthrough measurements and between analytical versus TOUGHREACT, respectively; for Scenario 1 at $40{ }^{\circ} \mathrm{C}$ : 0.68, 0.40; for Scenario 2 at $60{ }^{\circ} \mathrm{C}: 0.99,0.16$

indices of minerals correspond to the first cell encountered by fluid during flow). The root mean square errors (RMSE) are given in figure captions for each comparison.

In Fig. 7, dolomite permeability measurements at $40{ }^{\circ} \mathrm{C}$ and $60{ }^{\circ} \mathrm{C}$ do not match calculations. The measurements demonstrate oscillations at the beginning of the laboratory experiment. Based on observations made after conclusion of the experiment, the oscillations happened due to the effect on the flow field of broken dolomite particles within the fracture. According to Luhmann et al. (2014) and Luquot et al. (2014), fine particle migration and clogging can lead to permeability reduction during experiments. At the beginning of the experiments, the replacement of reactive fluid (brine- $\mathrm{CO}_{2}$ ) with saline fluid (only brine) and temperature and pressure equilibrium in the autoclave may also influence flow velocity. The system reached the target temperatures after approximately $3 \mathrm{~h}$. On reaching equilibrium between brine- $\mathrm{CO}_{2}$ and dolomite, the permeability patterns stopped changing over time. According to the literature, dolomite reactivity is 10-100 times slower than for calcite (Nogues et al. 2013). Therefore, more time is needed for the dolomite samples to stabilize the measurement.

The analytical algorithm at both temperatures shown in Fig. 7 slightly underestimates the permeability of dolomite compared to the cubic-law prediction in TOUGHREACT. If we examine further the results shown in Figs. 8 and 9, the comparison between the specific surface areas, kinetic rates, and fracture porosity estimations agree with analytical predictions. As we expressed in Sect. 1.1, in TOUGHREACT the empirical exponent is set to 3 in the power-law equation, and this likely yields an underestimation or overestimation of permeability. According to Smith et al. (2017), a wide range of dissolution front features are related to reactive fluid flow through well-sorted pore distributions or through cemented fossil fragments. These can enhance interaction between reactive fluid and crystals. In this way, the empirical exponent value of $n=3$ (cubic-law) or a higher value can be obtained. In contrast, if the reactive fluid flows through large fracture pathways, the interaction decreases and the result is a more acidic $\mathrm{pH}$. The lower interaction restricts mineral dissolution and localizes dissolution along single fractured regions.

The analytical predictions agree well with TOUGHREACT as can be seen in Figs. 8 and 9. In particular, the fracture porosity matches well with results from TOUGHREACT. It can be again noted that the TOUGHREACT PetraSIM interface does not demonstrate the results of matrix block parameters (e.g., matrix porosity, matrix reaction surface area). 
(a)

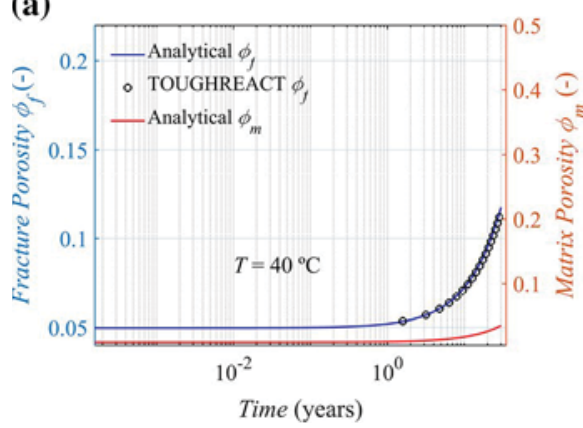

(b)

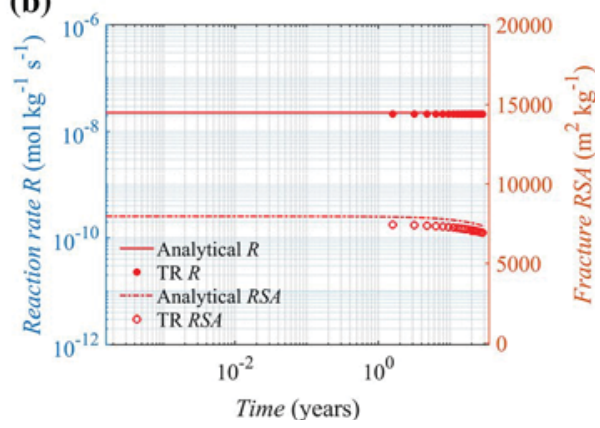

Fig. 8 Halen borehole (76-E-243) dolomite samples, Scenario 1, $1366 \mathrm{~m}$ at $40{ }^{\circ} \mathrm{C}$. a Fracture and matrix porosity over time. b Reaction rates $(R)$ and fracture reactive surface areas $(R S A)$ over time. Color code: red-dolomite. TR: TOUGHREACT. Calculated $\mathrm{pH}$ with TR is 5.49 and constant over time
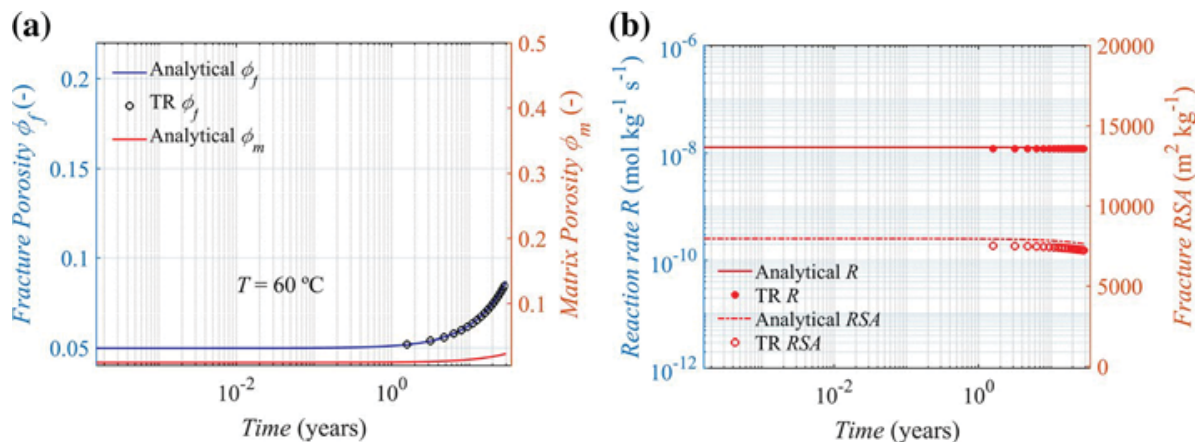

Fig. 9 Halen borehole (76-E-243) dolomite samples, Scenario 2, $1200 \mathrm{~m}$ at $60{ }^{\circ} \mathrm{C}$. a Fracture and matrix porosity over time. b Reaction rates $(R)$ and fracture reactive surface areas $(R S A)$ over time. Color code: red-dolomite. Calculated $\mathrm{pH}$ with TR is 5.36 and constant over time

Therefore, we only show analytical calculation results. The initial values of the specific surface areas were first calculated analytically with Eqs. 5 and/or 17 set to the TOUGHREACT simulator for all scenarios. In addition, TOUGHREACT requires specification of either the fracture or the matrix reactive surface areas of each mineral or the total surface areas of both fracture and matrix blocks because the simulator does not take into account separate fracture and matrix surface areas. Reactive surface areas of minerals on fracture walls are calculated from the fracture-matrix interface area/volume ratio (Xu et al. 2008). We discuss TOUGHREACT calculation methods further in Sect. 8.

In Figs. 8 and 9, the reaction rate of dolomite slightly decreases and changes in the reactive surface are small. However, porosity increases more than two times its initial value. These results indicate that the reactive fluid-rock interface area barely changes over time and the dissolution kinetics of dolomite mostly drives the porosity change.

Limestone experimental permeability measurements again do not match calculations but provide an approximate initial permeability value for benchmarking the models. The measurements at $40{ }^{\circ} \mathrm{C}$ and $60{ }^{\circ} \mathrm{C}$ shown in Fig. 10 have relatively stable permeability patterns over time. In contrast, the permeability for the limestone sample at $100{ }^{\circ} \mathrm{C}$ was more erratic during the experiment. It decreased approximately one order of magnitude 

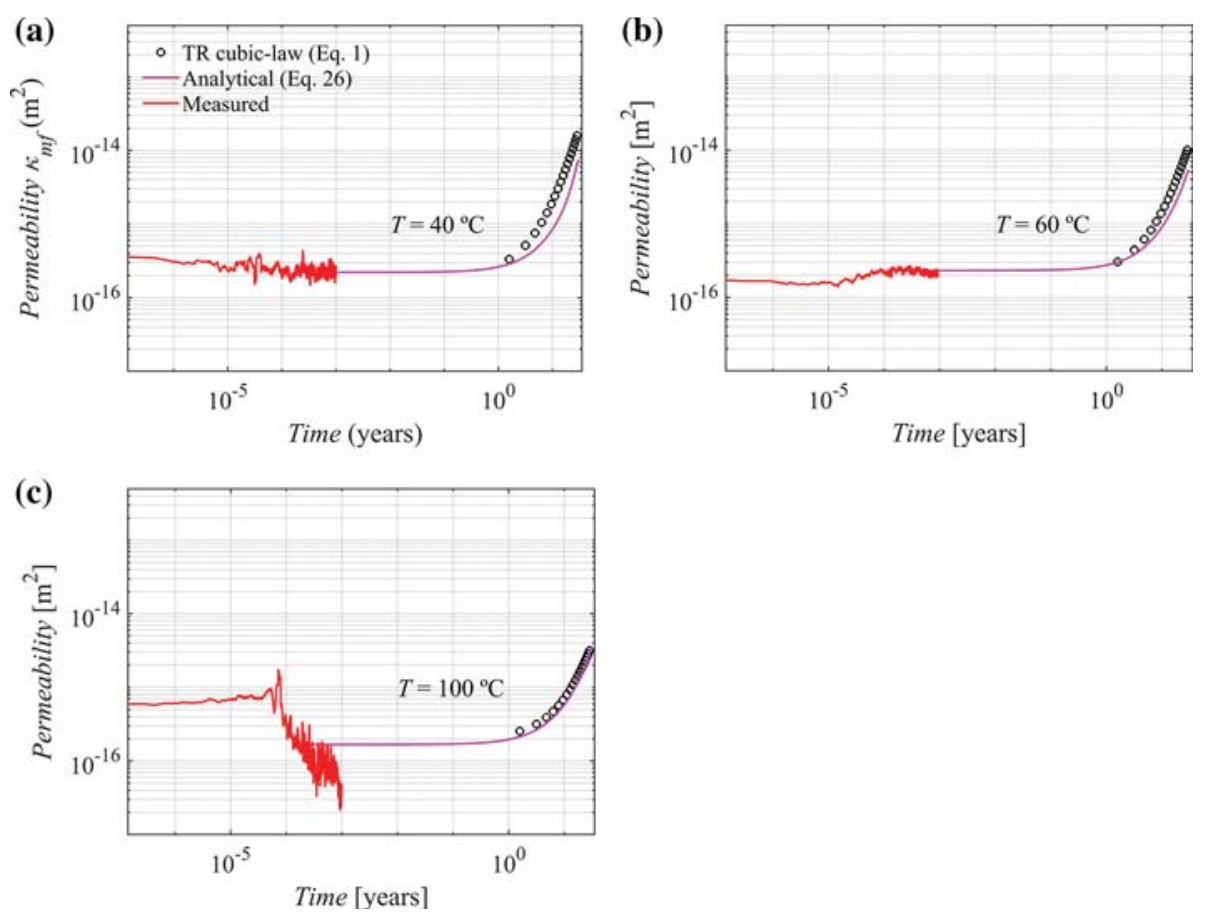

Fig. 10 Fracture permeability results for the Turnhout borehole (17-E-225) limestone samples: a Scenario $3,2188.5 \mathrm{~m}$, sample 3 at $40^{\circ} \mathrm{C}$; b Scenario $4,2188.5 \mathrm{~m}$, sample 1 at $60^{\circ} \mathrm{C}$; c Scenario $5,2188.5 \mathrm{~m}$, sample 2 at $100{ }^{\circ} \mathrm{C}$. RMSE between analytical versus flow-through measurements and between analytical versus TOUGHREACT, respectively; for Scenario 3 at $40{ }^{\circ} \mathrm{C}$ : $0.15,0.87$; for Scenario 4 at $60{ }^{\circ} \mathrm{C}: 0.12,0.75$; Scenario 5 at $100{ }^{\circ} \mathrm{C}: 0.99,0.21$

within the first $4 \mathrm{~h}$, and there is a second decreasing trend after $7 \mathrm{~h}$. Luhmann et al. (2012) observed similar fluctuations at $100{ }^{\circ} \mathrm{C}$ and indicated that during reactive fluid flow, accumulations of $\mathrm{CO}_{2}$ generated pressure pulsations due to temporary obstructions by exsolution and re-dissolution of $\mathrm{CO}_{2}$. Fluid flow at higher temperatures and higher driving pressure can avert exsolution of $\mathrm{CO}_{2}$ gas dissolved in brine (e.g., partial pressure of $\mathrm{CO}_{2}$ of 4.5-5.5 MPa at $100{ }^{\circ} \mathrm{C}$; Duan and Sun 2003; Duan et al. 2006). Due to high pressures, mineral precipitation in this sample is unlikely to be due to $\mathrm{CO}_{2}$ exsolution. Observation of the limestone experiment at $100{ }^{\circ} \mathrm{C}$ after the flow-through performance demonstrates that precipitation of some secondary aqueous species in brine $(\mathrm{NaCl}$ or $\mathrm{CaCl})$ occurred through the stainless steel and iron pipe connections in contact with brine- $\mathrm{CO}_{2}$ led to corrosion and plugged the plastic filter at the bottom of the sample prior to interaction of fluid with the sample. This shows that the high salinity of brine interaction with the stainless steel pipe connections has a significant impact on experiments.

The results for the limestone experiment shown in Fig. 10 demonstrate that the analytical algorithm slightly underestimates permeability at $40{ }^{\circ} \mathrm{C}$ and $60{ }^{\circ} \mathrm{C}$ and matches fairly at $100{ }^{\circ} \mathrm{C}$.

When we analyze again the other parameters of the simulations such as the fracture porosity, the reaction surface areas and the kinetic rates, we see a good agreement between the TOUGHREACT results and the analytical algorithm predictions (details of 
the results can be found in Appendix C). The reactive surface area of the calcite mineral decreases over time and the dissolved calcium ions interact with magnesium and $\mathrm{HCO}_{3}^{-}$ aqueous species, resulting in dolomite. However, it is still not clear why the permeability comparisons vary depending on the temperature, the type of rock, and the other characteristics.

\subsection{Comparison with the Reference Experimental Data}

Smith et al. (2017) performed flow-through experiments on dolomite and limestone samples at $60{ }^{\circ} \mathrm{C}$ to determine the exponent empirical value of " $n$ " for reactive transport simulations. As can be seen in Table 7, they proved in detail some of the measurement parameters of dolostone samples and limestones. In order to investigate further the impact of matrix porosity on the permeability and to verify our non-empirical solution, we calculated permeability with the TOUGHREACT simulator based on the values provided by Smith et al. (2017) for dolostone samples (e.g., A1520A, A1520B and A1444) in Fig. 12 and for limestone samples in Fig. 11 (e.g., V-1 and V-3).

In Fig. 11, the analytical solution predicts larger permeability change over time compared to the cubic law approach obtained with TOUGHREACT. On the other hand, the analytical solution agrees well with the Verma and Pruess (1988) equation if the empirical exponent is set to $n=6$ for the V- 1 sample and $n=8$ for the V-3 sample. The calcite is completely dissolved in V-3 between 50 and $55 \mathrm{~h}$ and this led to a steep trend as can be seen in Fig. $11 \mathrm{~b}$ for the analytical calculation. This empirical exponent value is nearly in agreement with what Smith et al. (2013, 2017) suggest for limestone (e.g., $n=6-8$, Table 7). According to the results demonstrated in Fig. 10, the larger pore and fracture connections of limestone likely augment the reactive surface area and increase the interaction between the reactive fluid and minerals, resulting in a larger amount of dissolution. Thus, the empirical exponent value becomes larger.

The comparison depicted in Fig. 12 demonstrates that the novel algorithm agrees well with the measurements of Smith et al. (2017) and the empirical exponent values (Table 7). Only the permeability result of A1520A calculated with the novel algorithm corresponds to a slight underestimation compared to the measured value of Smith et al. (2017). The crystal sizes and the height of the hydraulic apertures that we predicted may have an influence on these results, since these parameters are not precisely provided. The variation of empirical values between A1520A and A1520B can be accounted for via the the reaction rate of dolomite, which is approximately two orders of magnitude larger for A1520B (Table 7). Although sample A1520B has larger reaction rate for dolomite, the impact of dolomite dissolution on permeability is lower in contrast to the result of A1520A. The flow paths of A1520A are possibly longer that yield stronger dolomite dissolution and the permeability change is larger compared to A1520B. This indicates that empirical value mainly corresponds to the pore-fracture geometry.

In Figs. 13 and 14, the reactive surface areas and the kinetic rates of A-1520A and A-1520B do not undergo any major changes over time, but the volume ratio of the dolomite slightly declines. This may indicate that dolomite dissolves while the surface area of the pore-mineral interface hardly alters. Dissolution is likely restricted in localized flow paths. Therefore, predicted permeability has an empirical exponent value of less than 3 .

Figure 15 shows dimensionless analyses of the distinct permeability models, and it can be seen that the cubic-law approach (Eq. 1) agrees well with the Kozeny-Carman (Carman 1939) (Eq. 2) and Verma and Pruess (1988) (Eq. 3) models when the matrix porosity is 


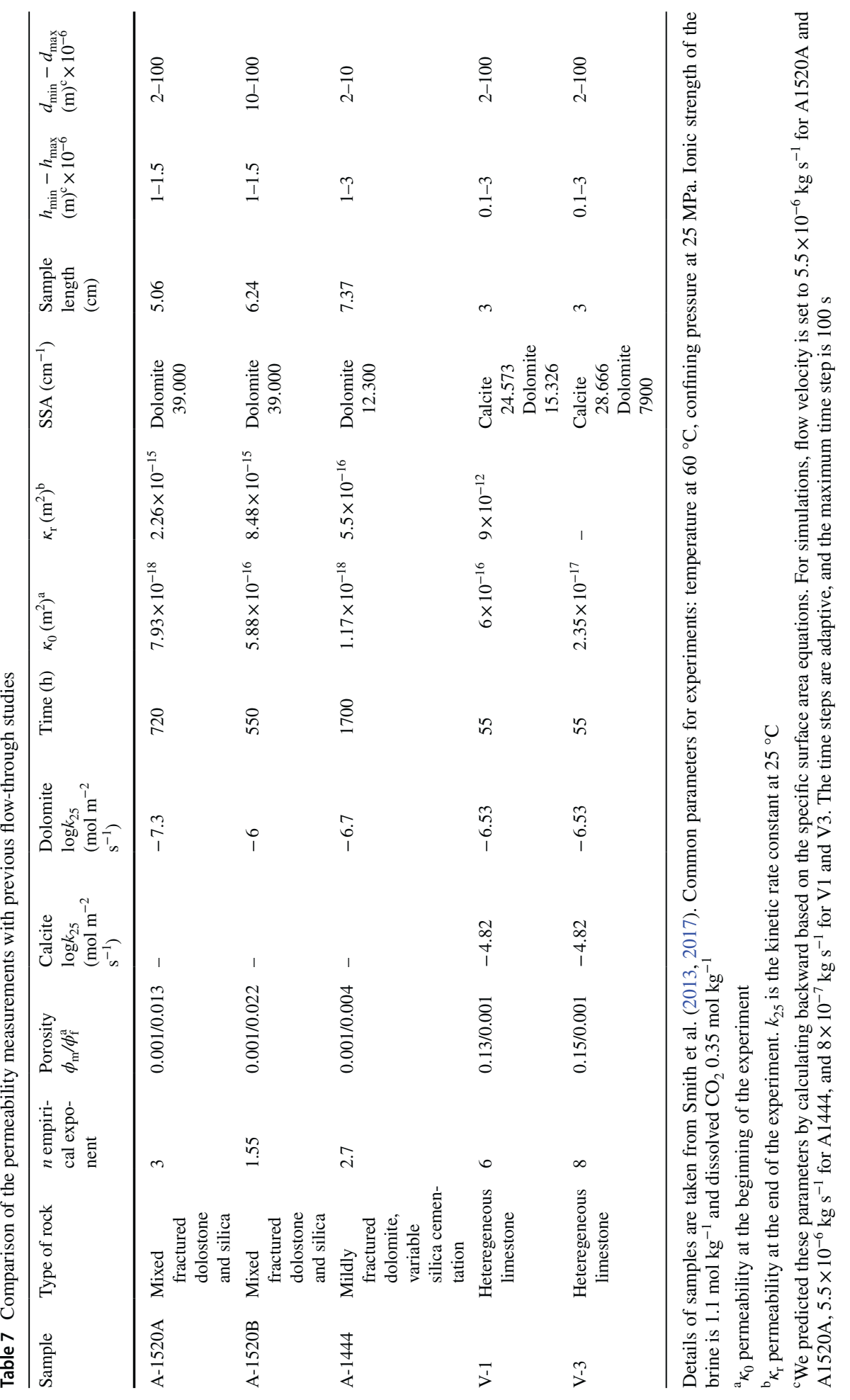



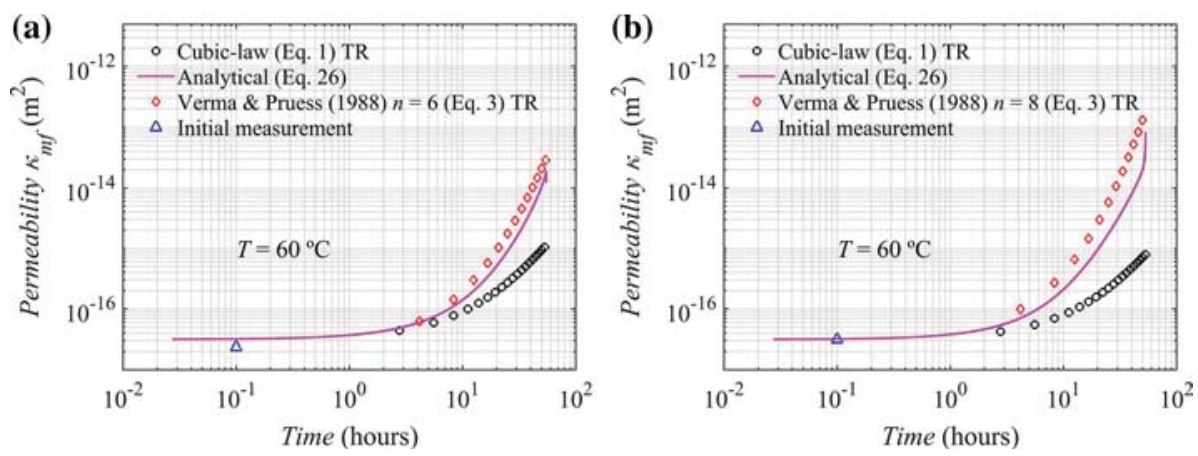

Fig. 11 Comparison of permeability models for limestone with measurements of Smith et al. (2013, 2017): a V-1 sample. b V-3 sample. TR: TOUGHREACT. RMSE between analytical versus Verma and Pruess (1988) with TR; for V-1: 0.60, for V-3: 0.95
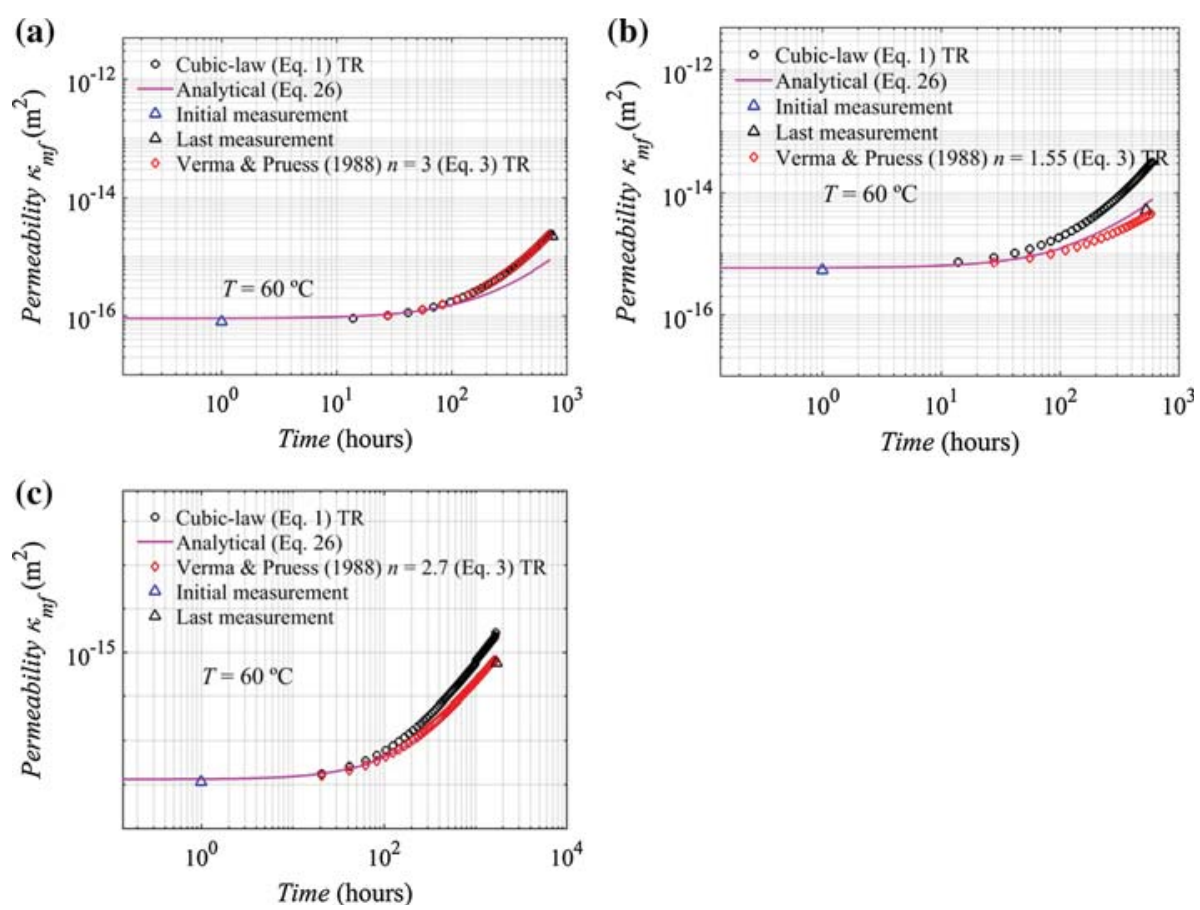

Fig. 12 Comparison of permeability models and measurements of Smith et al. (2017): a Dolostone A1520A sample at $60{ }^{\circ} \mathrm{C}$. b Dolostone A1520B sample at $60^{\circ} \mathrm{C}$. c Dolostone A1444 sample at $60{ }^{\circ} \mathrm{C}$. TR: TOUGHREACT. RMSE between analytical versus Verma and Pruess (1988) with TR; for A1520A: 0.60, for A1520B: 0.32, for A1444; 0.13

1\%. In contrast, the cubic-law and the Kozeny-Carman equations underestimate the permeability compared to the Verma and Pruess (1988) equation if the matrix porosity is $10 \%$. In both cases, the analytical algorithm results match results from the reference equation of Verma and Pruess (1988) with larger $n$ value. 

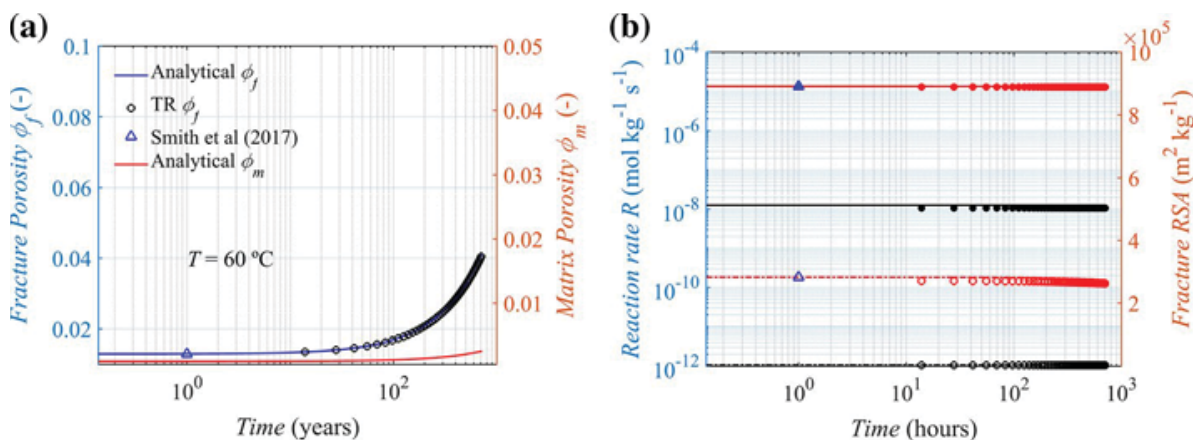

Fig. 13 Comparison of results of TOUGHREACT (circles) and novel algorithm predictions (lines) for the dolostone sample A1520A. The values given by Smith et al. (2017) as triangle symbols can be found in Table 7. a Fracture and matrix porosity over time. b Reaction rates ( $R$, plain symbols, and solid lines) and fracture reactive surface areas (RSA, empty symbols, and dash-dot lines) over time. Color code: red-dolomite, black-quartz. Calculated $\mathrm{pH}$ with TOUGHREACT is 4.93 and constant over time. According to Smith et al. (2017), the measured $\mathrm{pH}$ is around 4.6
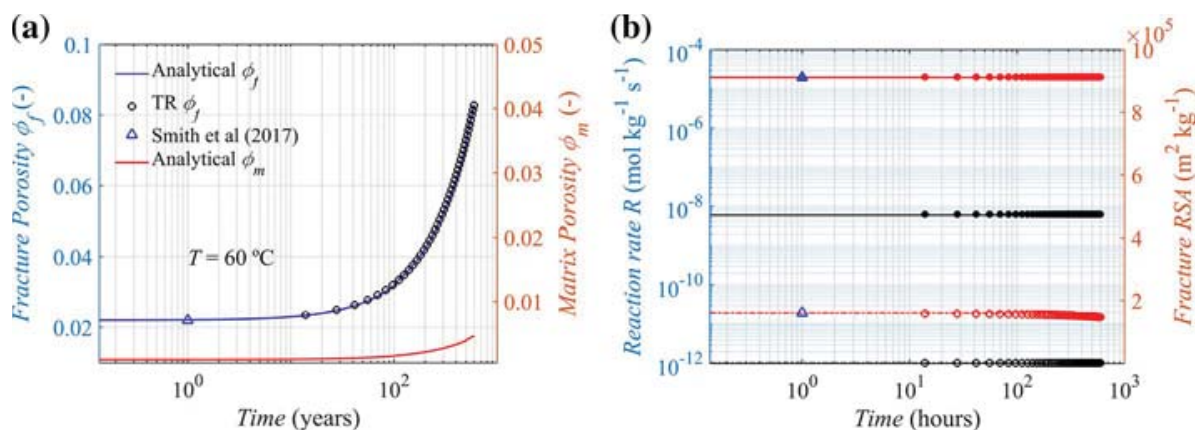

Fig. 14 Comparison of TOUHGREACT (circles) and analytical predictions (lines) for the dolostone sample A1520B. The values given by Smith et al. (2017) (triangle symbols) can be found in Table 7. a Fracture and matrix porosity over time. b Reaction rates ( $R$, plain symbols, and solid lines) and fracture reactive surface areas (RSA, empty symbols, and dash-dot lines) over time. Color code: red-dolomite, black—quartz. Calculated pH with TR is 4.06 and constant over time. According to Smith et al. (2017), the measured pH is around 4.3

Published permeability data from existing studies based on flow-through experiments are shown in Table 8. They generally demonstrate a one- or two-order of magnitude increase due to dissolution of calcite or dolomite. Compared to our experiments, the published experiments used brine at a lower ionic strength $\left(<2 \mathrm{~mol} \mathrm{~kg}^{-1}\right.$ of $\left.\mathrm{NaCl}\right)$ and with two to three times higher dissolved $\mathrm{CO}_{2}$. In contrast to the previous studies, the amount of dissolved $\mathrm{CO}_{2}$ is lower and salinity is higher in our experiments. Therefore, we may expect a lower impact of dissolution on the permeability over time compared to other previous studies with lower salinity and higher $\mathrm{CO}_{2}$ contents. 


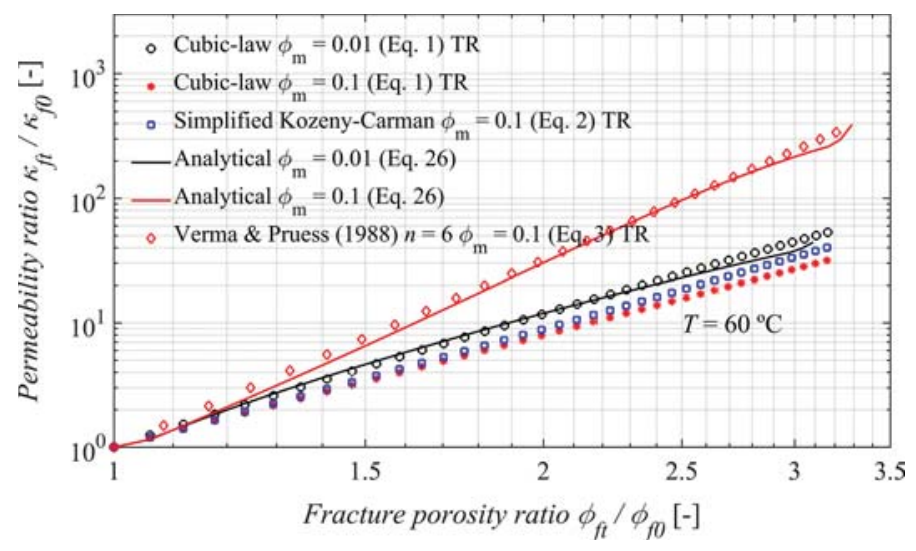

Fig. 15 Comparison ratios of distinct models for limestone with a matrix porosity of $1 \%$ and $10 \%$. Fracture porosity set constant to 5\%. TR: TOUGHREACT

\subsection{Chemical Concentration Results}

The brine $\mathrm{Na}^{+}, \mathrm{K}^{+}, \mathrm{Mg}^{2+}, \mathrm{Ca}^{2+}$ concentrations shown in Fig. 16 are compared with ICP-OES measurements following limestone-brine interaction at various temperatures with TOUGHREACT calculation results for scenarios 3-5 (Table 2). The reactive fluid was sampled during the flow-through experiments from the outlet of the autoclave apparatus, and the TOUGHREACT results were taken from the last cell (i.e., at the outlet).

Measured and calculated (TOUGHREACT) species concentrations remained stable over time and in agreement for $\mathrm{K}^{+}, \mathrm{Mg}^{2+}, \mathrm{Ca}^{2+}$, which have lower concentrations in the brine following rock-fluid interaction. On the other hand, while Na provided by TOUGHREACT results matches measured values at lower temperature, there is a mismatch at higher temperature (Table 9). There are three possible reasons. (i) ICP-OES species measurements took place at room temperature. (ii) The measurements of $\mathrm{Na}^{+}$based on a radial wavelength of $589.592 \mathrm{~nm}$ may have had an impact on the results (Table 2A). We examined the chemical interactions between brine- $\mathrm{CO}_{2}$ and limestone using PHREEQC with the Pitzer model for the same ionic strength during 1D fluid flow (ionic strength $3 \mathrm{~mol} \mathrm{~kg}^{-1}$ ). TOUGHREACT and PHREEQC results are identical. (iii) ICP-OES outputs the total amount of Na, including the species $\mathrm{NaCl}(\mathrm{aq}), \mathrm{NaHCO} 3$, and $\mathrm{NaOH}$, whereas the TOUGHREACT-PetraSIM provides only the amount of $\mathrm{Na}^{+}$.

We investigated the influence of non-saline $\mathrm{CO}_{2}$ fluid circulation on permeability by conducting flow-through experiments based on distilled water- $\mathrm{CO}_{2}\left(\mathrm{CO}_{2} \sim 0.2 \mathrm{~mol} \mathrm{~kg}{ }^{-1}\right)$. The non-saline fluids participate in dissolution that involves greater ion-exchange for both limestone and dolomite. The permeability of the samples increases by approximately one order of magnitude under distilled water- $\mathrm{CO}_{2}$ conditions at $60{ }^{\circ} \mathrm{C}$ over $9 \mathrm{~h}$. A similar impact can be seen in Table 8; the change in permeability at lower fluid ionic strength $\left(\sim 1 \mathrm{~mol} \mathrm{~kg}^{-1}\right)$ is larger than for fluid at higher ionic strength $\left(\sim 3 \mathrm{~mol} \mathrm{~kg}{ }^{-1}\right)$. ICP-OES analyses of fluid samples from the distilled water- $\mathrm{CO}_{2}$ experiments show that the cation changes in fluid, particularly the measured concentrations of $\mathrm{Ca}^{2+}$ and $\mathrm{Mg}^{2+}$ species, demonstrate constant dissolution over time (dissolution amount $\mathrm{Ca}^{2+} \sim 4.5 \times 10^{-4} \mathrm{~mol} \mathrm{~kg}^{-1}$ and $\mathrm{Mg}^{2+} \sim 3.3 \times 10^{-4} \mathrm{~mol} \mathrm{~kg}^{-1}$ ). 


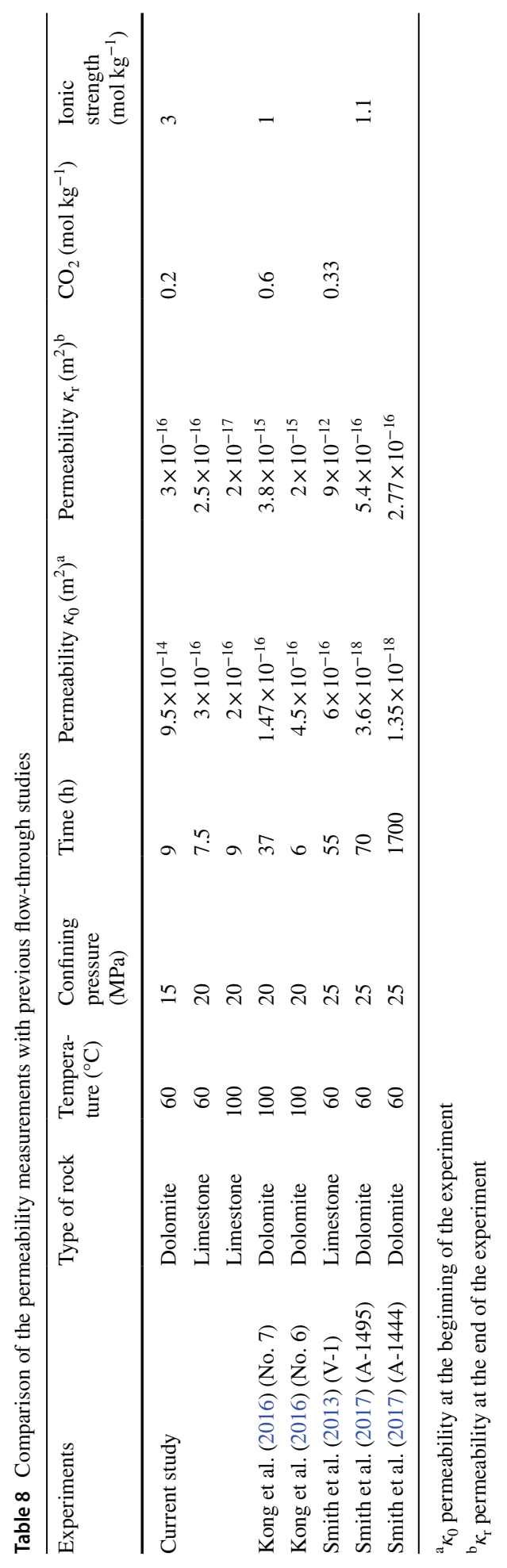



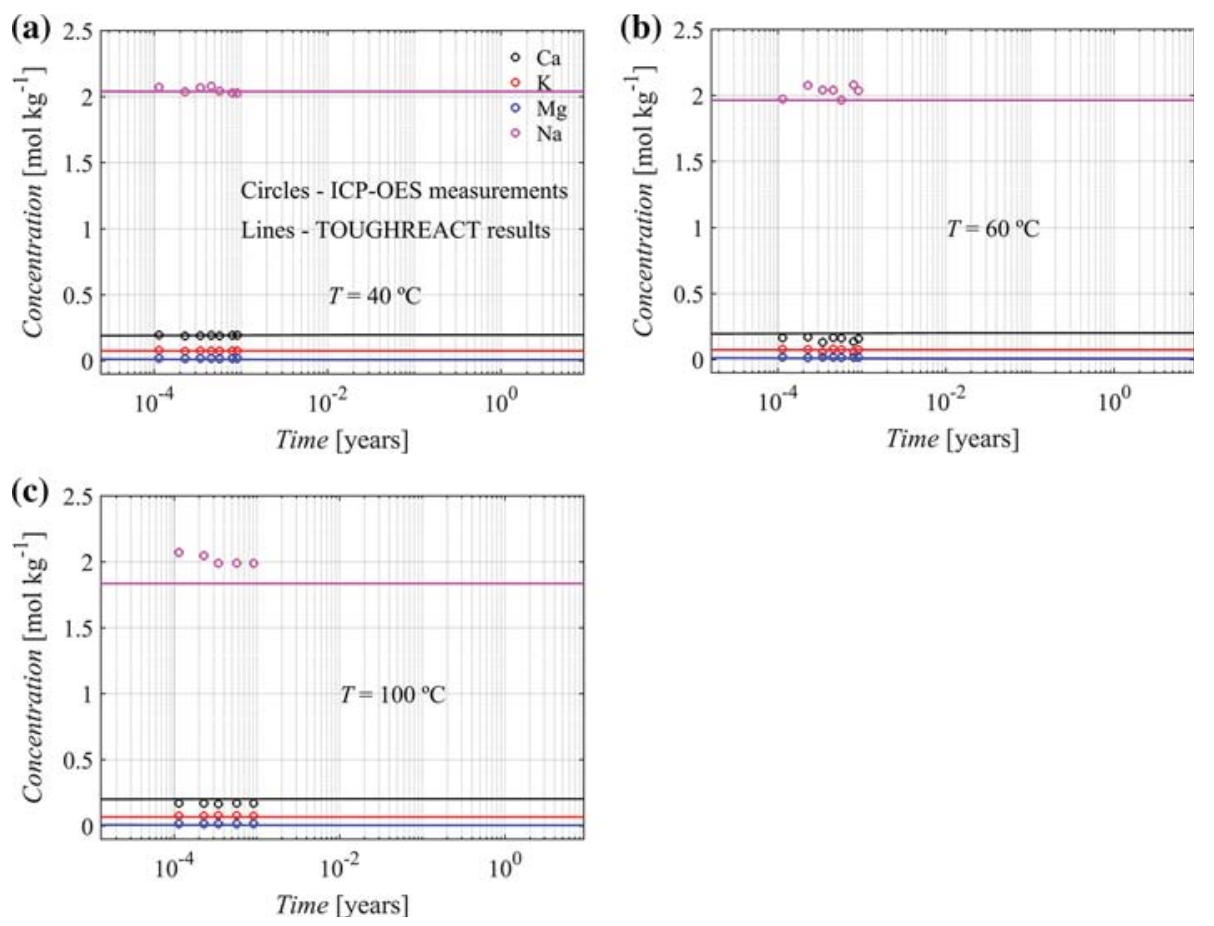

Fig. 16 Brine cation concentrations over time from reactive fluid flow-through experiments on Turnhout borehole (17-E-225) limestone samples (Table 2): a Scenario 3 at $40{ }^{\circ} \mathrm{C}$. b Scenario 4 at $60{ }^{\circ} \mathrm{C}$. c Scenario 5 at $100^{\circ} \mathrm{C}$. Circles are ICP-OES measurements, lines are TOUGHREACT results (symbology common to all three subplots)

Table 9 Root mean square errors of concentrations between TOUGHREACT and measurements

\begin{tabular}{lcccc}
\hline $\begin{array}{l}\text { Temperature } \\
\left({ }^{\circ} \mathrm{C}\right)\end{array}$ & $\mathrm{Ca}^{2+}$ & $\mathrm{K}^{+}$ & $\mathrm{Mg}^{2+}$ & $\mathrm{Na}^{+}$ \\
\hline 40 & 0.004 & 0.120 & 0.010 & 0.313 \\
60 & 0.048 & 0.130 & 0.009 & 0.369 \\
100 & 0.034 & 0.127 & 0.011 & 0.483 \\
\hline
\end{tabular}

\subsection{Comparison of Calculation Runtime with TOUGHREACT}

The novel analytical algorithm clearly has an advantage in terms of computation runtime compared to TOUGHREACT (Table 10). However, the analytical algorithm provides results based on local saturation index data whereas TOUGHREACT performs thermodynamic equilibration for each of the 400 cells in the domain. The measurements of Noiriel et al. (2009) indicate that thermodynamic equilibrium changes along the length of the sample in the flow direction (i.e., from inlet to outlet). Mesh size and time step specifications are important considerations. In general, both should be reduced until further reduction leads to minimal variation in the results. Finer meshes and smaller time steps are generally correlated with longer simulation times. An appropriate time marching method must be 
Table 10 Comparison of the calculation runtimes between TOUGHREACT and the novel analytical algorithm

\begin{tabular}{ll}
\hline Model & Runtime (s) $^{\mathrm{a}}$ \\
\hline Analytical algorithm for reactive transport & 3.5 \\
TOUGHREACT (400 cells) Scenario 1-Dolomite & 1625 \\
TOUGHREACT (400 cells) Scenario 2-Limestone & 1620 \\
\hline
\end{tabular}

${ }^{a}$ Hardware specifications: Intel i5-6200U Dual-Core $2.5 \mathrm{GHz}$ processor with $8 \mathrm{~GB}$ of RAM

selected. The analytical algorithm yields exact results that can serve as a basis for comparison with numerical solutions.

\section{Discussion}

The flow-through experiments were restricted to durations of $12-14 \mathrm{~h}$ due to both the restricted volume capacity of the 500D syringe pumps and laboratory regulations that prohibited nighttime use of facilities. In addition, the literature does not provide such data for reactive transport in fractured media, with the exception of Smith et al. (2017), who reported permeability measurements based on micro-fractured carbonate samples under reactive conditions. We otherwise present the first permeability measurements of fractured carbonate rock cores under reactive flow conditions suitable for initial model validation. A valuable contribution from a future study would involve experimental observation over much longer timescales - a couple of weeks or months. We expect that at such timescales, mineral dissolution and precipitation effects would be more obvious. The current capacity of the syringe pumps is not sufficient for circulating fluid through core samples over weeks or days. Therefore, we are at present restricted to what is presented here. Nevertheless, we made permeability evolution observations sufficient to obtain initial values and fitting for the analytical model and TOUGHREACT. The most important parameters governing calculation of mineral precipitation and dissolution are the kinetic rate constant and mineral saturation indices. The dolomite precipitation rate was slower than that of limestone precipitation, which affected its permeability relative to that of limestone.

Permeability predictions based on the analytical algorithm differ significantly from those calculated from the cubic-law equation (Civan 2001) implemented in TOUGHREACT due to the influence of the empirical constant $(n=3)$. RMSE based on the analytical (Eq. 26) and cubic law (Eq. 1) results increases as temperature rises. In contrast, RMSE based on flow-through measurements and the results of Eq. 26, decreases as temperature rises. The reason was a constant value for $n$ (i.e., that implies a fixed relationship between porosity and permeability); however, Figs. 11 and 12 show that $n$ values may in fact vary significantly with respect to pore-fracture geometry. As the fluid flow path is longer, the interaction between minerals and reactive fluid flow increases and leads to larger amount of mineral dissolution (Smith et al. 2017).

Mineral-specific surface area is another important source of difference between the permeability predictions. Noiriel et al. (2009) suggested the sugar-lump model to predict the reactive surface area for reactive transport models. In theory, the assumption of the sugar-lump model is similar to our fractal approach. However, the advantage of our fractal approach for predicting reactive surface area is that an empirical constant is not required. For dealing with fractures in TOUGHREACT, the areas are calculated with respect to 
fracture density, fracture porosity, and mean fracture diameter calculated based on the fracture spacing parameters defined in the MINC solver. The wall of a fracture is treated as a surface covered by mineral grains in the form of uniform hemispheres. The dual porosity model in MINC assumes homogeneous distribution of matrix blocks, but fracture sizes and therefore, reactive surface areas, may vary. The fractal distribution is based on the cumulative power-law function, which is easy to upscale. We note that Wei and Xia (2017) propose that the length distribution of fractures and fracture networks may not always follow the fractal law - that the fractal network may be multifractal or non-fractal. Further attention to fractal approaches for characterizing complex fracture networks is an important focus for future work. Nevertheless, the novel analytical algorithm provides an alternative approach far as describing the cumulative distributions of fracture and crystal sizes used for predicting the specific surface areas and permeability.

\section{Conclusion}

We have developed a predictive non-empirical analytical algorithm of dual porosity coupled with kinetic rate laws and mineral dissolution/precipitation for use in examining the impact of surface-controlled reactions on permeability. Here we have used the algorithm to calculate evolving system permeability during fluid circulation and fluid-rock interaction within systems relevant to deep geothermal energy exploitation, where temperature and pressure may be elevated and fluid may be saline and $\mathrm{CO}_{2}$-bearing.

From comparison of results based on the novel algorithm with those based on permeability models implemented in the well-known reactive transport code TOUGHREACT $\mathrm{v} 1.2$, the analytical model may have an advantage compared to the cubic-law approach (Civan 2001), the Verma and Pruess (1988) equation, and the simplified Kozeny-Carman equation (Carman 1939). The cubic-law approach incorporates a fixed empirical exponent for all fracture-pore geometries and therefore may underestimate or overestimate the permeability. The equation by Verma and Pruess (1988) also uses an empirical exponent but may provide an improved porosity-permeability relationship. Where the empirical exponent is fixed at values taken from Smith et al. (2017) for dolomite and limestone at $60{ }^{\circ} \mathrm{C}$, it leads to permeability values that compare well with those based on the novel algorithm. The use of empirical exponents relies on the literature data and mostly the exponent value is restricted for a specific system not linked to the system of interest. We have demonstrated that the empirical exponent mainly relates to pore-fracture geometry, which influences the amount of mineral dissolution rather than kinetic rates of dissolution. We believe that the parameters used in our algorithm are considerably easier to measure compared to the specific exponent values. The novel algorithm may therefore be a favorable option.

TOUGHREACT-based simulation of reactive surface area and matrix and fracture porosity matches well with analytical algorithm-based descriptions of observations on limestone and dolomite samples. The prediction of reactive surface area based on the cumulative distribution of hydraulic aperture and crystal radii of rocks may yield a convenient alternative approach to existing methods because the fractal approach provides a diverse range of reactive surface areas in natural systems. The new analytical algorithm may allow efficient reactive transport reservoir-scale simulation because the equations are derived from the fractal distributions of pores and fractures. In addition, the analytical algorithm may also provide an advantage in terms of computation time. The algorithm can be applied to evaluate quantitative relationships between porosity and permeability and 
reactive surface areas of sedimentary rocks and may be of particular use for reactive transport modeling in reservoir studies.

Acknowledgements This work was done with the support of the EU, ERDF, Flanders Innovation \& Entrepreneurship and the Province of Limburg (Grant: 1510487-SALK WP2: GeoWatt). Eva De Boever has been funded through the SNSF project QuantiCarb@Spring (nr.154810). The authors would also like to thank Dr. David Lagrou, Dr. Carlo Mol, and Dr. Mandy Duda for their assistance. The Geological Survey of Belgium is gratefully acknowledged for supplying core samples.

\section{Appendix A}

The autoclave, a specially designed X-ray transparent core holder, consisted of aluminum. The cylindrical samples were placed in a Viton sleeve, which was attached to porous spacers of metal at both sides of the sample. The confining pressure was controlled by the pressure of water surrounding the sample in an annulus between the sleeve and the aluminum tube. The applied stress acted in the perpendicular direction to the vertical specimen axis representing a normal loading condition. The samples were constrained in axial direction by gripped clamping of the core holder.

The pumps and heating jackets (up to $200{ }^{\circ} \mathrm{C}$ ) were controlled by syringe pumps (Teledyne ISCO, Lincoln NE, USA). Pump A and pump B were used for closed circulation to control upstream and downstream flow, where each pump had a capacity of $500 \mathrm{~mL}$ (500D syringe pump). Pump C was used to control confining pressure with a capacity of $260 \mathrm{~mL}$ (260D syringe pump). The reactor was used to mix brine and any $\mathrm{CO}_{2}$ gas and was only used for the experiments conducted with $\mathrm{CO}_{2}$ (Table 3). Experiments were limited to approximately $12 \mathrm{~h}$, mainly due to the restricted volume capacity of the 500D syringe pumps.

The core holder was placed on the rotational stage of the micro-CT apparatus as illustrated in Fig. 1b. The Volex 6 reconstruction software package (Fraunhofer-Allianz Vision 2012) was used to reconstruct of the conical X-ray beam. Upon their exit from the sample, attenuated X-rays were converted to a gray-value image. This used a reconstruction algorithm based on the Radon transform (Feldkamp et al. 1984). The gray values corresponded to measured X-ray intensities. Segmentation of the reconstructed gray-value images corresponded to the identification and separation of phases of interest (e.g., pores or grains and subsequent labeling process to create binary images). These binary images are usable for the evaluation of fractures within the examined limestone and dolomite samples.

The influence of different X-ray tube parameters was tested, and the best parameters were obtained for high-power application on the X-Ray transmission tube (Table 11).

The software package Avizo Fire, version 9.1.1@ (FEI Visualization Sciences Group 2016) was used for segmentation purposes. The total fracture porosity of the sample, $\phi_{\mathrm{f}}$, is the ratio of the pore space to the total number of voxels (Noiriel et al. 2009).

For the XRD measurements, the samples were manually crushed using a mortar and sieved below 500 microns and further reduced to submicron sizes using a McCrone Micronizing Mill with corundum crushing pellets. The sample powder was spiked with a reference of $0.3 \mathrm{~g}$ of zinc oxide added to $2.7 \mathrm{~g}$ of the samples as the internal standard technique, and for quantification a Rietveld-based refinement was used. The precision of measurement is $\sim 1 \%$.

We used ICP-OES data to estimate the chemistry of synthetic brine sample and to collect the amount of cation data for validating TOUGHREACT results. Stefan and Neubauer (2014) provide technical information regarding the ICP-OES device. The accuracy and precision of the measured mass of the cations are limited by several factors, such as 


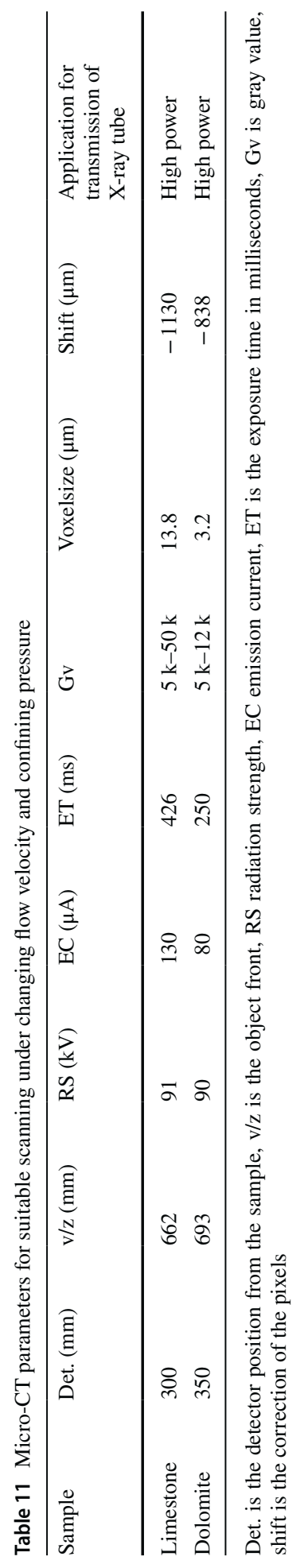


sensitivity drift, elemental/isotopic fractionation, matrix effects, interferences, and the lack of sufficiently matrix-matched reference materials (Lin et al. 2016). Therefore, to provide the analysis with appropriate calibration and correction, the fluctuations of the measurements must be normalized (De Ridder et al. 2002). The intensity of the energy emitted at the chosen wavelength is proportional to the concentration of that element in the analyzed sample. We determined the optimal normalization factor via software program WinLab 32 (PerkinElmer 2010) for the synthetic brine based on the following procedure. First we prepared mixtures of pure distilled water and synthetic brine at respective ratios of 1:10, 1:50, 1:100 and 1:1000. In addition, we used another calibration data from a test in which is conducted with a standard solution of 5 elements (e.g., $\mathrm{Al}^{3+}, \mathrm{Ca}^{2+}, \mathrm{K}^{+}, \mathrm{Mg}^{2+}$, and $\mathrm{Na}^{+}$). The standard solutions contain $1000 \mathrm{mg} \mathrm{l}^{-1}$ of each element, and dilutions are prepared with the identical ratios as described above for the first case. Mixing was achieved via an auto-machine to avoid contamination. Measurement and calibration results are compared with initial species concentrations in the synthetic brine in Table 12. The best match corresponds to a ratio of 1:1000 distilled water-synthetic brine.

\section{Appendix B}

The derivations of equations depicted in Sect. 3 are demonstrated here. The cross section areas and specific surface areas of pore space in matrix blocks and in the fracture network are derived based on the complimentary cumulative power function.

The particular expressions for power-law cumulative distribution function (CDF) is given as follows

$$
N(X \geq x)=\frac{\alpha-1}{x_{\min }^{-\alpha+1}} \int_{x}^{\infty} X^{-\alpha} \mathrm{d} X=\left(\frac{x}{x_{\min }}\right)^{-\alpha+1}
$$

$N$ is the cumulative number of parameter, $X$ is the integrated random variable $(x)$, and $\alpha$ is the likelihood estimation parameter. The parameter $\alpha$ can be replace with the fractal dimension $D_{\mathrm{f}}$ which is the slope of the best fit line on a logarithmic plot of the number

Table 12 The comparison of ICP-OES measurements and the expected concentration in brine composition at the ratio of $1: 1000$

\begin{tabular}{lll}
\hline & $\begin{array}{l}\text { Concentration measured with ICP-OES } \\
\mathrm{mol} \mathrm{kg}^{-1}(\text { ratio } 1: 1000)\end{array}$ & $\begin{array}{l}\text { Concentration of the initial values of the } \\
\text { synthetic brine when it is prepared mol } \\
\mathrm{kg}^{-1}(\text { ratio } 1: 1000)\end{array}$ \\
\hline $\mathrm{Na}^{+}(589.592)$ & 0.0023 & 0.0021 \\
$\mathrm{Na}^{+}(330.237)$ & 0.0023 & \\
$\mathrm{Na}^{+}(589.592 \mathrm{rad})$ & 0.0022 & \\
$\mathrm{~K}^{+}(766.490)$ & $3.703 / 9.49 \times 10^{-5}$ & $8.2 \times 10^{-5}$ \\
$\mathrm{~K}^{+}(404.721)$ & $-0.235--$ & \\
$\mathrm{K}^{+}(766.490 \mathrm{rad})$ & $8.88 \times 10^{-5}$ & \\
$\mathrm{~K}^{+}(404.721 \mathrm{rad})$ & $4.59 \times 10^{-5}$ & $2.1 \times 10^{-5}$ \\
$\mathrm{Mg}^{2+}(285.213)$ & $2.86 \times 10^{-5}$ & \\
$\mathrm{Mg}^{2+}(279.077)$ & $2.19 \times 10^{-5}$ & \\
$\mathrm{Mg}^{2+}(285.213 \mathrm{rad})$ & $2.3 \times 10^{-5}$ & \\
$\mathrm{Mg}^{2+}(279.077 \mathrm{rad})$ & $2.15 \times 10^{-5}$ & \\
$\mathrm{Ca}^{2+}(317.933)$ & $2.07 \times 10^{-4}$ & \\
$\mathrm{Ca}^{2+}(315.887)$ & $2.09 \times 10^{-4}$ & \\
$\mathrm{Ca}^{2+}(317.933 \mathrm{rad})$ & $2 \times 10^{-4}$ & $2 \times 10^{-4}$ \\
$\mathrm{Ca}^{2+}(315.887 \mathrm{rad})$ & & \\
\hline
\end{tabular}

The best correlations are highlighted in red-color font 
of parameter versus the size of the parameter, a description of the complexity of fractal patterns.

The derivation of Eq. 1B yields the probability density of variable $x$ as

$$
N=\left(\frac{x}{x_{\min }}\right)^{-D_{\mathrm{f}}+1} \frac{\partial}{\partial x}
$$

Differentiating both sides with respect to $x$ yields the number of variable as

$$
-\mathrm{d} N_{1}=\frac{D_{\mathrm{f}}-1}{x_{\min }\left(\frac{x}{x_{\min }}\right)^{D_{\mathrm{f}}}} \mathrm{d} x
$$

This CDF method can be applied for both cumulative pore and fracture distribution in a rock. Furthermore, it can be implemented in a reactive transport code to evaluate the rate of change in pores and in fractures.

The pore radii can be estimated as

$$
a_{\min / \max }=\frac{2 r_{\min / \max }}{\sqrt{2}}\left(\arctan \left(\sqrt{\frac{\phi_{\mathrm{m}}}{\left(1-\phi_{\mathrm{m}}\right)}}\right)+\left(\phi_{\mathrm{m}}-1\right)\left(\sqrt{\frac{\phi_{\mathrm{m}}}{\left(1-\phi_{\mathrm{m}}\right)}}\right)\right)
$$

where $a_{\min }$ and $a_{\max }$ are the minimum and maximum pore radii, $r_{\min }$ and $r_{\max }$ are the minimum and maximum crystal radii, and $\phi_{\mathrm{m}}$ is the matrix porosity. The maximum value of a crystal radius can be the mean value of the cumulative distribution.

The pore radii as a function of fractal dimension and porosity is given as

$$
a_{\mathrm{min}}^{-D_{\mathrm{fm}}}=\frac{a_{\mathrm{max}}^{D_{\mathrm{R}}-D_{\mathrm{fm}}} \phi_{\mathrm{m}}}{a_{\mathrm{min}}^{D_{\mathrm{R}}}}
$$

The cross section area of pore space in a rock matrix block can be estimated with the combination of Eq. 3B and 5B as

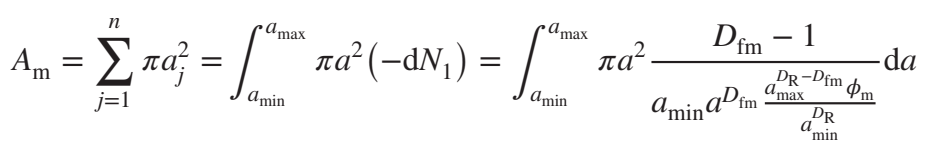

where $D_{\mathrm{fm}}$ is the fractal dimension of the matrix domain.

The integration of Eq. $6 \mathrm{~B}$ and alteration of pore radii due to reactive transport

$$
A_{\mathrm{mi}}(t)=\frac{\pi a_{\mathrm{min}}^{D_{\mathrm{E}}-D_{\mathrm{fm}}-1}(t) a_{\max }^{-D_{\mathrm{E}}}(t)\left(a_{\min }^{3}(t) a_{\mathrm{max}}^{D_{\mathrm{fm}}}(t)-a_{\mathrm{min}}^{D_{\mathrm{fm}}}(t) a_{\mathrm{max}}^{3}(t)\right)\left(D_{\mathrm{fm}}-1\right)}{\left(D_{\mathrm{fm}}-3\right) \phi_{\mathrm{m}}(t)} V f_{\mathrm{mi}}(t)
$$

in which $V_{\mathrm{fm}}$ is the volume fraction of a mineral.

The specific surface area of porous medium can be estimated as 


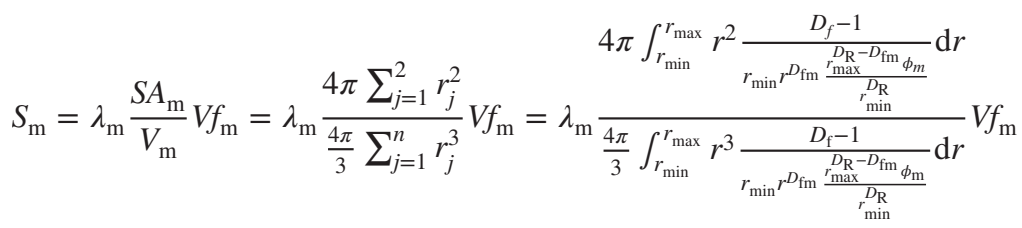

$\lambda_{\mathrm{m}}$ is the surface roughness in matrix domain, $S A_{\mathrm{m}}$ is the total surface area of a mineral in a matrix block, and $V_{\mathrm{m}}$ is the total volume of pore spaces in a matrix domain. After the integrations the specific surface is

$$
S_{\mathrm{m}}(t)=\lambda_{\mathrm{m}} \frac{3\left(r_{\min }^{3} r_{\mathrm{max}}^{D_{\mathrm{fm}}}-r_{\min }^{D_{\mathrm{fm}}} r_{\max }^{3}\right)\left(D_{\mathrm{fm}}-4\right)}{\left(r_{\min }^{4} r_{\max }^{D_{\mathrm{fm}}}-r_{\min }^{D_{\mathrm{fm}}} r_{\max }^{4}\right)\left(D_{\mathrm{fm}}-3\right)} V f_{\mathrm{m}}(t)
$$

In a similar manner, the cross section area of fracture network and the specific surface area can be estimated as

$$
\begin{gathered}
A_{\mathrm{f}}=\sum_{k=1}^{n} \sum_{j=1}^{m} w_{k} h_{j}=\int_{w_{\min }}^{w_{\max }} \int_{h_{\min }}^{h_{\max }} w h\left(-\mathrm{d} N_{1}\right)\left(-\mathrm{d} N_{2}\right) \\
A_{\mathrm{fi}}(t)=\left(\frac{\phi_{\mathrm{fi}}(t)}{\phi_{\mathrm{fi} 0}}\right) \frac{\left(w_{\min }^{2}(t)-w_{\max }^{2}(t)\left(\frac{w_{\max }(t)}{w_{\min }(t)}\right)^{-D_{\mathrm{ff}}}\right)\left(h_{\min }^{2}(t)-h_{\max }^{2}(t)\left(\frac{h_{\max }(t)}{h_{\min }(t)}\right)^{-D_{\mathrm{ff}}}\right)\left(D_{\mathrm{ff}}-1\right)^{2}}{w_{\min }(t) h_{\min }(t)\left(D_{\mathrm{ff}}-2\right)^{2}} V f_{\mathrm{fi}}(t)
\end{gathered}
$$

The specific surface area of fracture surface can be calculated as

$$
S_{\mathrm{f}}=\lambda_{\mathrm{f}} \frac{S A_{\mathrm{f}}}{V_{\mathrm{f}}} V f_{\mathrm{f}}=\frac{2 \sum_{s=1}^{z} l_{s}\left(\sum_{k=1}^{n} w_{k}+\sum_{j=1}^{m} h_{j}\right)}{\sum_{s=1}^{z} \sum_{k=1}^{n} \sum_{j=1}^{m} l_{s} w_{k} h_{j}}=\frac{2\left(\int_{w_{\min }}^{w_{\max }} w\left(-\mathrm{d} N_{2}\right)+\int_{h_{\min }}^{h_{\max }} h\left(-\mathrm{d} N_{1}\right)\right)}{\int_{w_{\min }}^{w_{\max }} \int_{h_{\min }}^{h_{\max }} w h\left(-\mathrm{d} N_{1}\right)\left(-\mathrm{d} N_{2}\right)}(1
$$

where $\lambda_{\mathrm{f}}$ is the surface roughness in fracture domain $V f_{\mathrm{f}}$ is the volume fraction of a mineral, $S A_{\mathrm{f}}$ is the total surface area of a mineral in matrix block, and $V_{\mathrm{f}}$ is the total volume of the fractures.

$$
\begin{aligned}
S_{\mathrm{fi}}(t)= & \lambda_{\mathrm{f}} \frac{2\left[-w_{\min }\left(\frac{w_{\max }}{w_{\text {min }}}\right)^{D_{\mathrm{ff}}} h_{\max }^{2}+h_{\min }\left(-w_{\max }^{2}+w_{\min }\left(\frac{w_{\max }}{w_{\text {min }}}\right)^{D_{\mathrm{ff}}}\left(w_{\min }+h_{\min }\right)\right)\left(\frac{h_{\max }}{h_{\text {min }}}\right)^{D_{\mathrm{ff}}}\right]}{\left(w_{\max }^{2}-w_{\text {min }}^{2}\left(\frac{w_{\max }}{w_{\text {min }}}\right)^{D_{\mathrm{ff}}}\right)\left(h_{\max }^{2}-h_{\text {min }}^{2}\left(\frac{h_{\max }}{h_{\min }}\right)^{D_{\mathrm{ff}}}\right)} \\
& \times \frac{\left(D_{\mathrm{ff}}-2\right)}{\left(D_{\mathrm{ff}}-1\right)} V f_{\mathrm{fi}}(t)
\end{aligned}
$$




\section{Appendix C}

The benchmarking results shown in Figs. 17, 18, and 19 are obtained at $40{ }^{\circ} \mathrm{C}, 60{ }^{\circ} \mathrm{C}$, and $100{ }^{\circ} \mathrm{C}$ temperatures for the limestone samples (Scenario 3-5; Table 2). The permeability comparison of these scenarios can be found in Fig. 10. The comparison results agree here well in common for the parameters of fracture porosity, reaction rate, volume ratio of minerals, and reaction surface area. In contrast to these parameter results which are in-line with the TOUGHREACT, the permeability results in Fig. 10 do not match due to the cubic-law (Eq. 1) prediction based on the fixed empirical exponent value.

(a)

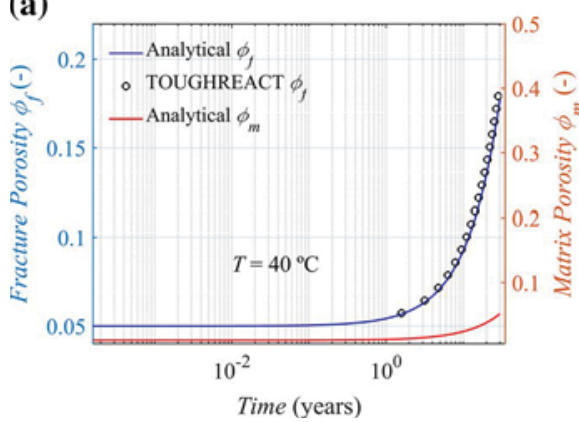

(b)

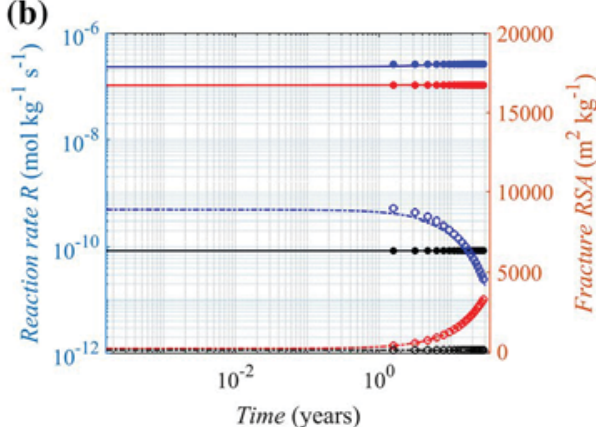

Fig. 17 Comparison results of TOUHGREACT (circles) and analytical predictions (lines) for the Turnhout borehole (17-E-225) limestone sample: Scenario 3, $2188.5 \mathrm{~m}$, sample 3 at $40{ }^{\circ} \mathrm{C}$. a Fracture and matrix porosity over time. b Reaction rates ( $R$, plain symbols, and solid lines) and fracture reactive surface areas (RSA, empty symbols, and dash-dot lines) over time. Color code: blue-calcite, red-dolomite, blackquartz. TR: TOUGHREACT. Calculated $\mathrm{pH}$ with TR is 5.56 and constant over time

(a)

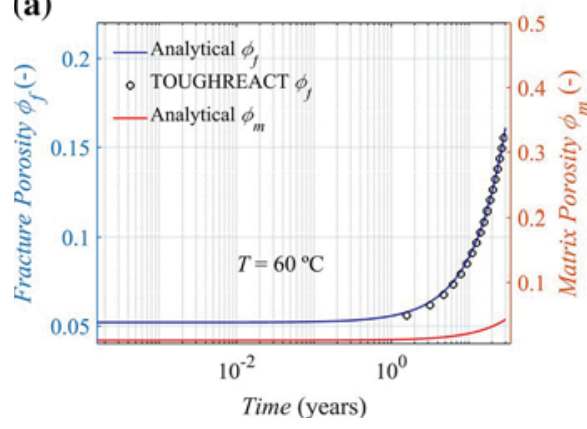

(b)

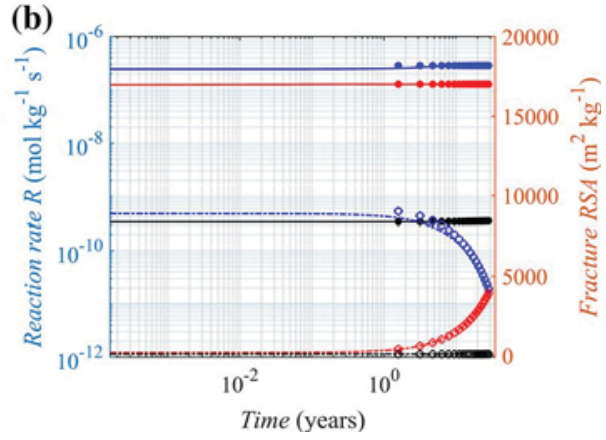

Fig. 18 Comparison results of TOUHGREACT (circles) and analytical predictions (lines) for the Turnhout borehole (17-E-225) limestone samples: Scenario 4, $2188.5 \mathrm{~m}$, sample 1 at $60{ }^{\circ} \mathrm{C}$. a Fracture and matrix porosity over time. b Reaction rates ( $R$, plain symbols, and solid lines) and fracture reactive surface areas (RSA, empty symbols, and dash-dot lines) over time. Color code: blue—calcite, red—dolomite, blackquartz. Calculated $\mathrm{pH}$ with TR is 5.44 and constant over time 
(a)

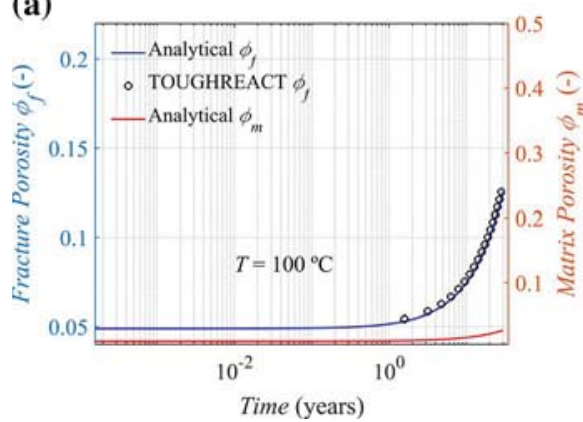

(b)

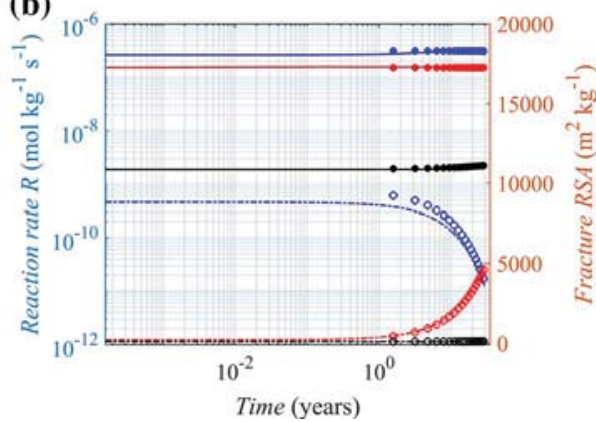

Fig. 19 Comparison results of TOUHGREACT (circles) and analytical predictions (lines) for the Turnhout borehole (17-E-225) limestone samples: Scenario 5, $2188.5 \mathrm{~m}$, sample 2 at $100{ }^{\circ} \mathrm{C}$. a Fracture and matrix porosity over time. b Reaction rates ( $R$, plain symbols, and solid lines) and fracture reactive surface areas (RSA, empty symbols, and dash-dot lines) over time. Color code: blue—calcite, red—dolomite, blackquartz. Calculated $\mathrm{pH}$ with TR is 5.34 and constant over time

\section{References}

Akın, S.: Temperature induced dissolution or precipitation in geothermal reservoirs and their effects on pressure transient analysis. In: Thirty-Seventh Workshop on Geothermal Reservoir Engineering. Stanford University, Stanford, CA, US (2012)

Antics, M., Sanner, B.: Status of geothermal energy use and resources in Europe. Proc. Eur. Geotherm. Congr 2007, 1-8 (2007)

Appelo, C.A.J., Postma, D.: Geochemistry, Groundwater and Pollution, 2nd edn. Balkema, Amsterdam (2005)

Bear, J.: Dynamics of Fluids in Porous Media. Dover Publication Inc, New York (1972)

British Petroleum Global: Report: The 64th edition of the BP statistical review of world energy. London, United Kingdom (2015)

Carman, P.C.: Permeability of saturated sands, soils and clays. J. Agric. Sci. 29, 262-273 (1939)

Civan, F.: Scale effect on porosity and permeability: kinetics, model, and correlation. AIChE J. 47(2), 11671197 (2001). https://doi.org/10.1002/aic.690470206

Deng, Y., Molins, S., Trebotich, D., Steefel, C., DePaolo, D.: Pore-scale numerical investigation of the impacts of surface roughness: upscaling of reaction rates in rough fractures. Geochim. Cosmochim. Acta 239, 374-389 (2018). https://doi.org/10.1016/j.gca.2018.08.005

De Ridder, F., Pintelon, R., Johan Schoukens, J., Navez, J., Andre, L., Dehairs, F.: An improved multiple internal standard normalisation for drift in LA-ICP-MS measurements. J. Anal. At. Spectrom. 17, 1461-1470 (2002). https://doi.org/10.1039/b207715a

Duan, Z., Sun, R., Zhu, C., Chao, I.: An improved model for the calculation of $\mathrm{CO}_{2}$ solubility in aqueous solutions containing $\mathrm{Na}^{+}, \mathrm{K}^{+}, \mathrm{Ca}^{2+}, \mathrm{Mg}^{2+}, \mathrm{Cl}^{-}$, and $\mathrm{SO}_{4}{ }^{2-}$. Mar. Chem. 98(2-4), 131-139 (2006). https://doi.org/10.1016/j.marchem.2005.09.001

Duan, Z., Sun, R.: An improved model calculating $\mathrm{CO}_{2}$ solubility in pure water and aqueous $\mathrm{NaCl}$ solutions from 273 to $533 \mathrm{~K}$ and from 0 to 2000 bar. Chem. Geol. 193(3-4), 257-271 (2003). https://doi. org/10.1016/S0009-2541(02)00263-2

EGEC: European Geothermal Energy Council Report: Geothermal Declaration. Brussels, Belgium (2018)

Emmanuel, S., Berkowitz, B.: Effects of pore-size controlled solubility on reactive transport in heterogeneous rock. Geophys. Res. Lett. 34, 1-5 (2007). https://doi.org/10.1029/2006GL028962

Erol, S., Fowler, S.J., Harcouët-Menou, V., Laenen, B.: An analytical model of porosity-permeability for porous and fractured media. Transp. Porous Media 120(2), 327-358 (2017). https://doi.org/10.1007/ s11242-017-0923-Z

FEI Visualization Sciences Group, Avizo: 3D Analysis Software for Scientific and Industrial Data. Windows Version 9.1.1 (2016)

Feldkamp, L.A., Davis, L.C., Kress, J.W.: Practical cone-beam algorithm. J. Opt. Soc. Am. 16, 612-619 (1984). https://doi.org/10.1364/JOSAA.1.000612 
Fraunhofer-Allianz Vision, Volex: Volume Explorer Software. Windows Version 6.3, Fraunhofer IIS, Fürth, Germany (2012)

Gallup, D.L.: Production engineering in geothermal technology: a review. Geothermics 38(3), 326-334 (2009). https://doi.org/10.1016/j.geothermics.2009.03.001

Gouze, P., Luquot, L.: X-ray microtomography characterization of porosity, permeability and reactive surface changes during dissolution. J. Contam. Hydrol. 120-121, 45-55 (2011). https://doi.org/10.1016/j. jconhyd.2010.07.004

Hao, Y., Smith, M.M., Sholokhova, Y., Carroll, S.A.: $\mathrm{CO}_{2}$-induced dissolution of low permeability carbonates. Part II: numerical modeling of experiments. Adv. Water Resour. 62, 388-408 (2013). https://doi. org/10.1016/j.advwatres.2013.09.009

Huq, F., Haderlein, S.B., Cirpka, O.A., Nowak, M., Blum, P., Grathwohl, P.: Applied Geochemistry Flowthrough experiments on water-rock interactions in a sandstone caused by $\mathrm{CO}_{2}$ injection at pressures and temperatures mimicking reservoir conditions. Appl. Geochem. 58, 136-146 (2015). https://doi. org/10.1016/j.apgeochem.2015.04.006

Idaho National Laboratory: Report: INL/EXT-06-11746, The Future of Geothermal Energy. Massachusetts Institute of Technology. Idaho Falls, U.S. (2006)

Kolditz, O., Bauer, S., Bilke, L., Böttcher, N., Delfs, J.O., Fischer, T., Görke, U.J., Kalbacher, T., Kosakowski, G., McDermott, C.I., Park, C.H., Radu, F., Rink, K., Shao, H., Shao, H.B., Sun, F., Sun, Y.Y., Singh, A.K., Taron, J., Walther, M., Wang, W., Watanabe, N., Wu, Y., Xie, M., Xu, W., Zehner, B.: OpenGeoSys: an open-source initiative for numerical simulation of thermo-hydro-mechanical/ chemical (THM/C) processes in porous media. Environ. Earth Sci. 67(2), 589-599 (2012). https://doi. org/10.1007/s12665-012-1546-x

Kong, X., Leal, A.M.M., Saar, M.O.: Implications of hydrothermal flow-through experiments on deep geothermal energy utilization. In: European Geothermal Congress. 19-24 Sept 2016. Strasbourg, France (2016)

Laenen, B.: Report in Dutch: 2003/ETE/095, Lithostratigrafie van het pre-Tertiair in Vlaanderen Deel II: Dinantiaan \& Devoon, Flemish Research Institute for Technology, Mol, Belgium (2003)

Laenen, B., Broothaers, M., Harcouët-Menou, V. Loveless, S.: The Balmatt deep geothermal project in northern Belgium. In: Conference Poster, Deep Geothermal Days. Paris, France (2014)

Lasaga, A.C.: Chemical kinetics of water-rock interactions. J. Geophys. Res. Solid Earth. 89(B6), 40094025 (1984). https://doi.org/10.1029/JB089iB06p04009

Lin, J., Liu, Y., Yang, Y., Hu, Z.: Calibration and correction of LA-ICP-MS and LA-MC-ICP-MS analyses for element contents and isotopic ratios. Solid Earth Sci. 1, 5-27 (2016). https://doi.org/10.1016/j.sesci .2016 .04 .002

Luhmann, A.J., Kong, X.-Z., Tutolo, B.M., Ding, K., Saar, M.O., Seyfried Jr., W.E.: Permeability reduction produced by grain reorganization and accumulation of exsolved $\mathrm{CO}_{2}$ during geologic carbon sequestration: a new $\mathrm{CO}_{2}$ trapping mechanism. Environ. Sci. Technol. 47, 242-251 (2012)

Luhmann, A.J., Kong, X.-Z., Tutolo, B.M., Garapati, N., Bagley, B.C., Saar, M.O., Seyfried Jr., W.E.: Experimental dissolution of dolomite by $\mathrm{CO} 2$-charged brine at $100{ }^{\circ} \mathrm{C}$ and 150 bar: evolution of porosity, permeability, and reactive surface area. Chem. Geol. 380, 145-160 (2014). https://doi. org/10.1016/j.chemgeo.2014.05.001

Luquot, L., Gouze, P.: Experimental determination of porosity and permeability changes induced by injection of $\mathrm{CO}_{2}$ into carbonate rocks. Chem. Geol. 265(1-2), 148-159 (2009). https://doi.org/10.1016/j. chemgeo.2009.03.028

Luquot, L., Rodriguez, O., Gouze, P.: Experimental characterization of porosity structure and transport property changes in limestone undergoing different dissolution regimes. Transp. Porous Media 101, 507-532 (2014)

Menke, H.P., Bijeljic, B., Andrew, M.G., Blunt, M.J.: Dynamic three-dimensional pore-scale imaging of reaction in a carbonate at reservoir conditions. Environ. Sci. Technol. 49(7), 4407-4414 (2015). https ://doi.org/10.1021/es505789f

Menke, H.P., Andrew, M.G., Blunt, M.J., Bijeljic, B.: Reservoir condition imaging of reactive transport in heterogeneous carbonates using fast synchrotron tomography-effect of initial pore structure and flow conditions. Chem. Geol. 428, 15-26 (2016). https://doi.org/10.1016/j.chemgeo.2016.02.030

Muchez, P., Viaene, W., Marshall, J.D.: Origin of shallow burial cements in the Late Visran of the Campine Basin, Belgium. Sedim. Geol. 73, 257-271 (1991)

Nogues, J.P., Fitts, J.P., Celia, M.A., Peters, C.A.: Permeability evolution due to dissolution and precipitation of carbonates using reactive transport modeling in pore networks. Water Resour. Res. 49, 60066021 (2013). https://doi.org/10.1002/wrcr.20486

Noiriel, C., Daval, D.: Pore-scale geochemical reactivity associated with $\mathrm{CO}_{2}$ storage: new frontiers at the fluid-solid interface. Acc. Chem. Res. 50(4), 759-768 (2017) 
Noiriel, C., Gouze, P., Bernard, D.: Investigation of porosity and permeability effects from microstructure changes during limestone dissolution. Geophys. Res. Lett. 31(24), L24603 (2004). https://doi. org/10.1029/2004GL021572

Noiriel, C., Luquot, L., Madé, B., Raimbault, L., Gouze, P., van der Lee, J.: Changes in reactive surface area during limestone dissolution: an experimental and modelling study. Chem. Geol. 265, 160-170 (2009). https://doi.org/10.1016/j.chemgeo.2009.01.032

Noiriel, C., Steefel, C.I., Yang, L., Ajo-Franklin, J.: Upscaling calcium carbonate precipitation rates from pore to continuum scale. Chem. Geol. 318-319, 60-74 (2012). https://doi.org/10.1016/j.chemg eo.2012.05.014

Orywall, P., Drüppel, K., Kuhn, D., Kohl, T., Zimmermann, K., Eiche, E.: Flow through experiments on the interaction of sandstone with Ba rich fluids at geothermal conditions. Geotherm. Energy 5(23), 1-24 (2017). https://doi.org/10.1186/s40517-017-0079-7

Palandri, J.L., Kharaka, Y.K.: A compilation of rate parameters of water-mineral interaction kinetics for application to geochemical modeling: USGS report 2004-1068. U.S. Geological Survey. Menlo Park, CA, US (2004)

Pape, H., Clauser, C., Iffland, J.: Permeability prediction for reservoir sandstones based on fractal pore space geometry. Geophysics 64(5), 1447-1460 (1999)

Parkhurst, D.L., Appelo, C.A.J.: Description of input and examples for PHREEQC version 3-a computer program for speciation, batch-reaction, one-dimensional transport, and inverse geochemical calculations. U.S. Geological Survey Techniques and Methods. Amsterdam, Netherlands (2013). https://doi. org/10.1016/0029-6554(94)90020-5

PerkinElmer: Software Guide: WinLab32 for ICP instrument control software. PerkinElmer Inc. Waltham, MA, US (2010)

Petitclerc, E., Laenen, B., Lagrou, D., Hoes, H.: Geothermal energy use, country update for Belgium. In: European Geothermal Congress, 19-24 Sept 2016. Strasbourg, France (2016)

PetraSIM: Thunderhead engineering software user manual 2017. Thunderhead Engineering Consultants Inc. Manhattan, KS, US (2017)

Phillips, S.L., Ozbek, H., Igbene, A., Litton, G.: Report: LBL-11586. Viscosity of NaCl and other solutions up to $350 \mathrm{C}$ and $50 \mathrm{MPa}$ Pressures, Lawrence Berkeley Laboratory. Berkeley, CA, US (1980). http:// www.osti.gov/scitech/servlets/purl/6731414/

Richter, M.: Report: summary of new drilling technologies. IEA Geothermal. Jülich, Germany (2017)

Satman, A., Ugur, Z., Onur, M.: The effect of calcite deposition on geothermal well inflow performance. Geothermics 28(3), 425-444 (1999). https://doi.org/10.1016/S0375-6505(99)00016-4

Seibt, A.: Private report: geochemical analysis of downhole samples (geothermal well Mol GT01/Belgium). BWG Geochemische Beratung GmbH, Neubrandenburg, Germany (2016)

Şimşek, Ş., Yıldırım, N., Gülgör, A.: Developmental and environmental effects of the Kızıldere geothermal power project, Turkey. Geothermics 34(2), 234-251 (2005). https://doi.org/10.1016/j.geothermic s.2004.12.005

Smith, M.M., Hao, Y., Carroll, S.A.: Development and calibration of a reactive transport model for carbonate reservoir porosity and permeability changes based on $\mathrm{CO}_{2}$ core-flood experiments. Int. J. Greenh. Gas Control 57, 73-88 (2017). https://doi.org/10.1016/j.ijggc.2016.12.004

Smith, M.M., Sholokhova, Y., Hao, Y., Carroll, S.A.: $\mathrm{CO}_{2}$-induced dissolution of low permeability carbonates, part I: characterization and experiments. Adv. Water Resour. 62, 370-387 (2013)

Soong, Y., Howard, B.H., Dilmore, R.M., Haljasmaa, I., Crandall, D.M., Zhang, L., Zhang, W., Lin, R., Irdi, G.A., Romanov, V.N., Mclendon, T.R.: Original Research Article $\mathrm{CO}_{2}$ /brine/rock interactions in Lower Tuscaloosa formation. Greenh. Gases Sci. Technol. 837, 824-837 (2016). https://doi. org/10.1002/ghg.1611

Steefel, C.I., Van Cappellen, P.: A new kinetic approach to modeling water-rock interaction: the role of nucleation, precursors, and Ostwald ripening. Geochim. Cosmochim. Acta 54(10), 2657-2677 (1990). https://doi.org/10.1016/0016-7037(90)90003-4

Steefel, C.I., DePaolo, D.J., Lichtner, P.C.: Reactive transport modeling: an essential tool and a new research approach for the Earth sciences. Earth Planet. Sci. Lett. 240(3-4), 539-558 (2005). https://doi. org/10.1016/j.eps1.2005.09.017

Stefan, C., Neubauer, K.: White Paper: Single Particle Inductively Coupled Plasma Mass Spectrometry: Understanding How and Why. PerkinElmer Inc., Waltham (2014)

Thorhallsson, S.: Common problems faced in geothermal generation and how to deal with them. In: Workshop for Decision Makers on Geothermal Projects and Management. Naivasha, Kenya (2005)

Tutolo, B.M., Luhmann, A.J., Kong, X.-Z., Saar, M.O., Seyfried Jr., W.E.: Experimental observation of permeability changes in dolomite at $\mathrm{CO}_{2}$ sequestration conditions. Environ. Sci. Technol. 48, 2445-2452 (2014) 
Tutolo, B.M., Luhmann, A.J., Kong, X.-Z., Saar, M.O., Seyfried Jr., W.E.: CO2 sequestration in feldspar-rich sandstone: coupled evolution of fluid chemistry, mineral reaction rates, and hydrogeochemical properties. Geochim. Cosmochim. Acta 160, 132-154 (2015). https://doi.org/10.1016/j.gca.2015.04.002

Vaughan, P.J.: Analysis of permeability reduction during flow of heated, aqueous fluid through Westerly Granite. In: Coupled Processes Associated with Nuclear Waste Repositories. Academic Press Inc. 22(4), 529-540 (1987)

Verma, A., Pruess, K.: Thermo-hydrological conditions and silica redistribution near high- level nuclear wastes emplaced in saturated geological formations. J. Geophys. Res. Solid Earth. 93, 1159-1173 (1988). https://doi.org/10.1029/JB093iB02p01159

Wei, W., Xia, Y.: Geometrical, fractal and hydraulic properties of fractured reservoirs: a mini-review. Adv. Geo Energy Res. 1(1), 31-38 (2017)

Wang, H., Bernabé, Y., Mok, U., Evans, B.: Localized reactive flow in carbonate rocks: core-flood experiments and network simulations. J. Geophys. Res. Solid Earth 121, 7965-7983 (2016). https://doi. org/10.1002/2016JB013304

Warren, J.E., Root, P.J.: The behavior of naturally fractured reservoirs. Soc. Pet. Eng. 3(03), 245-255 (1963). https://doi.org/10.2118/426-PA

Xu, T., Sonnenthal, E., Spycher, N., Pruess, K.: TOUGHREACT version 1.2.1: A simulation program for non-isothermal multiphase reactive transport in variably saturated geologic media. Report LBNL-55460-2008. Lawrence Berkeley National Laboratory. Berkeley, CA, US (2008). https://doi. org $/ 10.2172 / 943451$

Xu, T., Spycher, N., Sonnenthal, E., Zhang, G., Zheng, L., Pruess, K.: TOUGHREACT version 2.0: A simulator for subsurface reactive transport under non-isothermal multiphase flow conditions. Comput. Geosci. 37, 763-774 (2011)

$\mathrm{Xu}$, T., Feng, G., Shi, Y.: On fluid-rock chemical interaction in $\mathrm{CO}_{2}$-based geothermal systems. J. Geochem. Explor. 144, 179-193 (2014). https://doi.org/10.1016/j.gexplo.2014.02.002

Yeh, G.T., Li, Y., Jardine, P.M., Burgos, W.D., Fang, Y., Li, M.H., Siegel, M.D.: Report ORNL/ TM-2004/103: HYDROGEOCHEM 4.0: A coupled model of fluid flow, thermal transport, and hydrogeochemical transport through saturated-unsaturated media: Version 4.0', Oak Ridge National Laboratory, Oak Ridge, TN, US (2004)

Yu, B., Li, J.: Some fractal characters of porous media. Fractals 9(3), 365-372 (2001)

Publisher's Note Springer Nature remains neutral with regard to jurisdictional claims in published maps and institutional affiliations.

\section{Affiliations}

\section{Selçuk Erol ${ }^{1,2} \cdot$ Sarah Jane Fowler ${ }^{3} \cdot$ Mathias Nehler $^{4} \cdot$ Eva De Boever $^{5}$. Virginie Harcouët-Menou ${ }^{1} \cdot$ Ben Laenen $^{1}$}

Flemish Institute for Technological Research (VITO), Boeretang 200, 2400 Mol, Belgium

2 Department of Earth and Environmental Sciences, Celestijnenlaan 200E, KU Leuven, 3001 Heverlee, Belgium

3 School of Earth Sciences, University of Bristol, Wills Memorial Building, Queens Road, Bristol BS8 1RJ, UK

4 International Geothermal Centre Bochum, Lennershofstraße 140, 44801 Bochum, Germany

5 Department of Geosciences - Geology, University of Fribourg, Chemin du Musée 6, 1700 Fribourg, Switzerland 